Florida International University

FIU Digital Commons

FIU Electronic Theses and Dissertations

University Graduate School

$10-18-2013$

\title{
The Effect of Contemporary Hydrologic Modification on Vegetation Community Composition Distinctness in the Florida Everglades
}

Ewan Isherwood

Florida International University, eishe001@fiu.edu

DOI: $10.25148 /$ etd.FI13120912

Follow this and additional works at: https://digitalcommons.fiu.edu/etd

Part of the Plant Biology Commons, and the Terrestrial and Aquatic Ecology Commons

\section{Recommended Citation}

Isherwood, Ewan, "The Effect of Contemporary Hydrologic Modification on Vegetation Community Composition Distinctness in the Florida Everglades" (2013). FIU Electronic Theses and Dissertations. 1027.

https://digitalcommons.fiu.edu/etd/1027

This work is brought to you for free and open access by the University Graduate School at FIU Digital Commons. It has been accepted for inclusion in FIU Electronic Theses and Dissertations by an authorized administrator of FIU Digital Commons. For more information, please contact dcc@fiu.edu. 
FLORIDA INTERNATIONAL UNIVERSITY

Miami, Florida

THE EFFECT OF CONTEMPORARY HYDROLOGIC MODIFICATION ON VEGETATION COMMUNITY COMPOSITION DISTINCTNESS IN THE FLORIDA EVERGLADES

\author{
A thesis submitted in partial fulfillment of \\ the requirements for the degree of \\ MASTER OF SCIENCE \\ in \\ BIOLOGY \\ by
}

Ewan Isherwood

2013 
To: Dean Kenneth G. Furton

College of Arts and Sciences

This thesis, written by Ewan Isherwood, and entitled The Effect of Contemporary Hydrologic Modification on Vegetation Community Composition Distinctness in the Florida Everglades, having been approved in respect to style and intellectual content, is referred to you for judgment.

We have read this thesis and recommend that it be approved.

\begin{tabular}{rr}
\hline James Heffernan \\
\hline Kenneth Feeley \\
\hline Jennifer Richards \\
\hline Evelyn Gaiser, Major Professor
\end{tabular}

Date of Defense: October 182013

The thesis of Ewan Isherwood is approved.

Dean Kenneth G. Furton

College of Arts and Sciences

Dean Lakshmi N. Reddi

University Graduate School

Florida International University, 2013 


\section{ACKNOWLEDGMENTS}

I express thanks to my chair, Dr. Evelyn Gaiser, for taking me on as a student and pushing me to understand the Everglades and statistical analyses better, as well as help me with administrative tasks when I was unable to do them myself. I also thank my committee members: Dr. Kenneth Feeley, who gave an excellent perspective to me on ecological concepts outside of the Everglades, and Dr. Jennifer Richards, whose botanical knowledge of the Everglades and more broadly community ecology principles was critical in shaping many parts of my thesis.

I owe a debt of gratitude to my academic supervisor, Dr. James Heffernan, whose help, often daily, from my first day through to submission of my thesis, has undeniably been essential to me earning this degree. His passion for science and teaching is boundless, and the scientific and literary skills I have gained through his encouragement I will carry with me forever.

I thank my funding sources: the United States Army Corps of Engineers and South Florida Water Management District for help with all research costs. For site access, I also thank Everglades National Park.

I am grateful for the academic support given by Dr. Michael Ross, Dr. Jay Sah, Megan Fork and Kristofor Voss, and for Megan's help with thesis revisions on multiple occasions.

None of this would have been possible without all of the help I received with fieldwork: our lab manager, Lawrence Lopez, as well as Mario Cisneros, Virginia Fernandez, Megan Fork, Dr. James Heffernan, Sean Koester, Jay Munyon, Pablo Ruiz, Alexandra Saldana, Gabriel Sone, Dr. Danielle Watts, and the Ross Lab at Florida International University. I also thank lan Jones for helping me with several administrative tasks when I was not able to. 
Finally, I would like to thank my family and friends for their support. Certainly, without your help and goodwill I would not be in this position today. I especially would like to thank my wife, Megan Fork, whose belief in my ability and help with every step and every issue I have faced has been phenomenal. 


\title{
ABSTRACT OF THE THESIS \\ THE EFFECT OF CONTEMPORARY HYDROLOGIC MODIFICATION ON VEGETATION COMMUNITY COMPOSITION DISTINCTNESS IN THE FLORIDA EVERGLADES
}

\author{
by \\ Ewan Isherwood \\ Florida International University, 2013 \\ Miami, Florida \\ Professor Evelyn Gaiser, Major Professor
}

The historic Everglades Ridge and Slough landscape maintained regularly spaced and elevated sawgrass ridges interspersed among exposed deeper-water sloughs; however, widespread but irregular hydrologic modification has degraded much of this landscape patterning. My study assessed the effects of hydrologic modification on vegetation community distinctness within the Ridge and Slough landscape through sampling species composition at fine-scales along a hydrologic gradient to measure the magnitude of segregation of species among patch types. The results show that vegetation community and topographic variation degradation is widespread, with distinctness differences proceeding and possibly being driven by topographic variation loss. Vegetation responses to past hydrologic regime modifications are likely affected by temporal lags; however, vegetation distinctness regeneration may also be hindered by a vegetatively homogeneous alternative stable state. Hydrologic regime restoration is critical for Ridge and Slough patterned landscape reestablishment, but management targets are complicated by vegetation response lags and possibly alternative stable states. 


\section{TABLE OF CONTENTS}

CHAPTER

PAGE

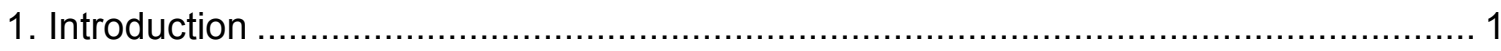

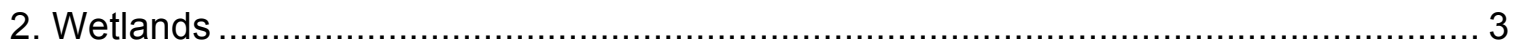

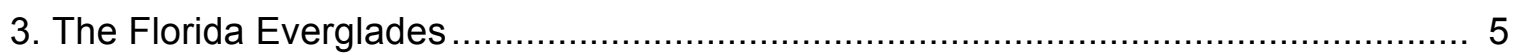

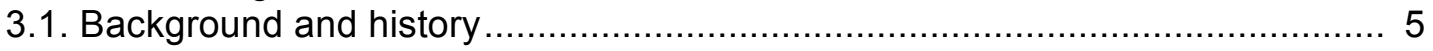

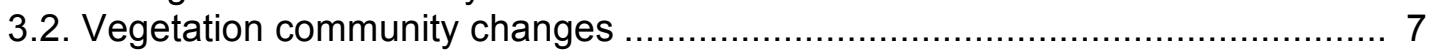

3.3. Vegetation community and topographic variation loss ............................ 10

3.4. Vegetation communities and leading indicators of ecological change ............ 12

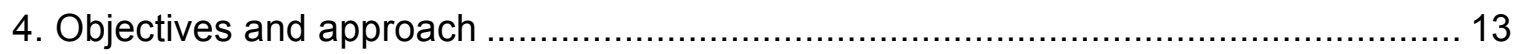

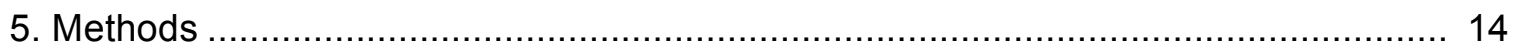

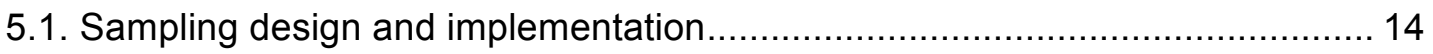

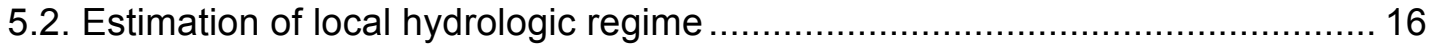

5.3. Analysis of Vegetation Composition and Distinctness.................................. 17

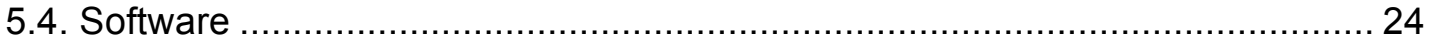

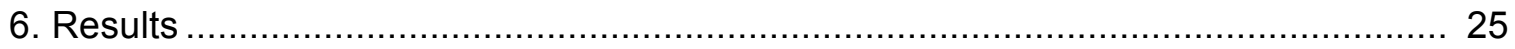

6.1. Vegetation composition and distinctness ............................................... 25

6.2. Hydrologic and topographic effects on distinctness ................................. 28

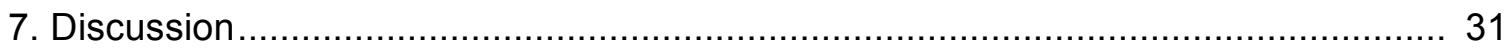

7.1. Vegetation community distinctness in the Ridge and Slough landscape ......... 31

7.2. Vegetation community distinctness and hydrologic regime modification ......... 34

7.3. Vegetation community distinctness and topographic variation ........................ 35

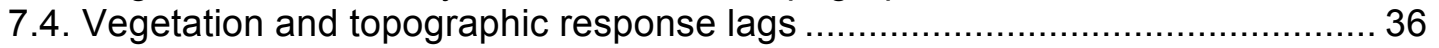

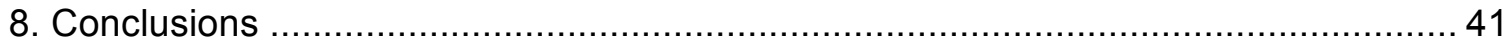

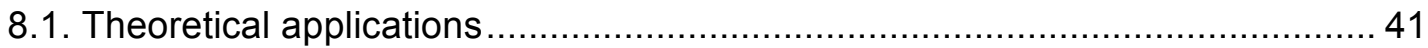

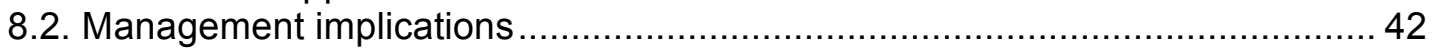

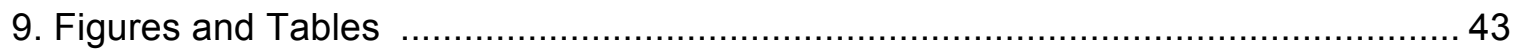

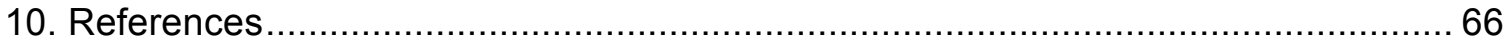




\section{LIST OF FIGURES}

FIGURE

PAGE

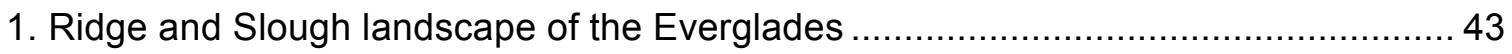

2. Site map with 27 landscape blocks (PSUs) from two years of sampling .................. 44

3. Two PSUs ordinated by NMDS and clustered by k-means ............................... 45

4. Schematic of lag scenarios following a reduction in the hydrologic regime ............... 46

5. Major species' abundances within the most common field designated communities . 47

6. Hydrologic regimes for major communities among basins ................................. 48

7. NMDS ordination scores for the three most abundant vegetation communities ......... 49

8. NMDS ordination site scores within PSUs rotated to the hydrologic axis .................50

9. Sawgrass relative abundance for each cluster within each PSU ........................... 51

10. Community statistics: count, cluster segregation, and hydrologic regimes.............. 52

11. Odds Ratio Test for k-means derived clusters within communities ........................ 53

12. Vegetation community distinctness along the hydrologic gradient ........................ 54

13. Vegetation community distinctness' association with topographic variation ............55

14. Vegetation community distinctness and topographic variation counts and KDE ......56

15. The k-means cluster distance difference in MWD across the hydrologic gradient ... 57

16. Sawgrass abundance and MWD correlation across the hydrologic gradient........... 58

17. Mantel $r$ vegetation-topography correlation across the hydrologic gradient ............59

18. Vegetation community distinctness across the Ridge and Slough landscape .......... 60

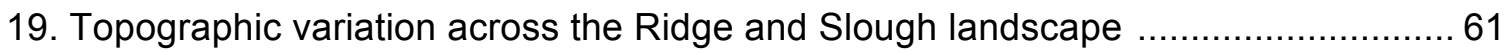

20. The k-means difference in MWD across Ridge and Slough landscape ...................62

21. Sawgrass_-MWD correlation across Ridge and Slough landscape ...................... 63

22. Mantel $r$ vegetation-topography across Ridge and Slough landscape..................... 64

23. Conservation status for each PSU across the Ridge and Slough landscape ........... 65 


\section{Introduction}

Ecological communities within landscapes range from being composed of discrete sets of species to a continuously varying blend of any number of individual ecological patches (Levin and Paine 1974). Patchiness may arise through unevenness in abiotic environmental drivers exerting stress upon a landscape (Sousa 1984) or variation in edaphic properties (Wiens et al. 1985). However, patchiness may also arise biotically through competition among species for a finite resource (MacArthur and Levins 1964, Peltzer 2001), such as nutrients, water or light (Connell 1983), allelopathy limiting other species' ability to compete (Vivanco et al. 2004, Bais et al. 2006), mutualistic facilitative interactions among sets of species within communities (Stachowicz 2001), dispersal dynamics (Levine and Murrell 2003), scale-dependent feedbacks between vegetation and underlying abiotic environments (Rietkerk et al. 2004, Rietkerk and van de Koppel 2008), or a complex mixture of any of the above (Callaway and Walker 1997). Moreover, the contrast between community patches can be heightened by the presence of ecosystem engineers modifying physical habitats (Gilad et al. 2004, Crain and Bertness 2005).

However, ecological communities are not static: variation in spatial patterning both within and among patches through time arise from changes in the environmental drivers exerting stress on landscapes (Callaway and Walker 1997). Current (Allen and Breshears 1998, Feeley and Rehm 2012) but also past (Milchunas and Lauenroth 1995) abiotic and biotic drivers of ecological change affect patches by influencing species movements. Patch changes through time may be assessed through measuring shifting species composition (Walker et al. 1999) and species interactions within and among patches (Morellet et al. 2007, Tylianakis et al. 2007), patch functionality (Carpenter and 
Brock 2006, Scheffer et al. 2009), or through measuring species response times to relatively slight environmental variations (Scheffer and Carpenter 2003).

In addition, ecological boundaries between adjacent patches are often critical components of landscape patterning and changes (Strayer et al. 2003), as boundaries frequently exhibit abrupt shifts in environmental conditions and, consequently, often have different ecological characteristics compared those to within patches (Gosz 1992, Ries et al. 2004, Kark and van Rensburg 2006).

Ecosystems affected by changing abiotic or biotic drivers may undergo abrupt ecological regime shifts among alternative stable states (Scheffer et al. 2001, Beisner et al. 2003). Alternative stable states within ecosystems may impede environmental managers' restoration efforts, as transitions between states may be dependent on a regime shift's direction; that is, the ecosystems exhibit hysteresis (Scheffer et al. 2001, Beisner et al. 2003). To prevent undesirable regime shifts from occurring, it is therefore critical that leading indicators of environmental change-characteristics that can signify when landscapes are about to undergo possible rapid changes_are determined (Groffman et al. 2006). Patch changes and leading indicators of ecological change analyses are often focused on variation through time; however, if environmental drivers exerting stress across a landscape are uniform in type, but not necessarily strength, it is often more pragmatic to conduct analyses in a spatial context as a proxy for temporal variation (Groffman et al. 2006). Identifying measurable and quantifiable ecological characteristics that indicate thresholds of ecosystem change are important for environmental managers whose goals include limiting or preventing ecosystem degradation (Niemi and McDonald 2004, Scheffer et al. 2009). 


\section{Wetlands}

The heterogeneous and sometimes harsh flooding-drying regimes of wetlands support a range of both emergent and submergent plant species (Keddy 2010, Mitsch and Gosselink 2011). The hydrologic regime is the dominant driver creating and maintaining heterogeneous patches in wetlands, as species, which frequently define patch characteristics, usually occupy restricted hydrologically derived niche spaces (van der Valk 1981, Spence 1982, Weiher and Keddy 1995, Noon 1996). Heterogeneous patches are most apparent in wetlands that contain abrupt topographic variation and distinct ecological boundaries (van der Valk 1981, Zedler 2000). However, both patches and their ecological boundaries are affected by changing environmental conditions, which frequently results in patches becoming less pronounced within a landscape (van der Valk 1981, Zedler 2000, Magee and Kentula 2005, Stallins 2006, Post et al. 2007, Corenblit et al. 2007).

The stress exerted on wetland vegetation by the hydrologic regime, as exemplified by periodic dry-downs, governs species' physiology and life-history strategies (Foster et al. 1983, Magee and Kentula 2005). Wetland vegetation therefore possess unique and diverse reproductive strategies, including rapid response times, turnover, and proliferation in favorable conditions (Keddy 2010, Mitsch and Gosselink 2011). Wetland vegetation also have various structural adaptations particularly in response to drying stress (Jackson and Colmer 2005). These include, but are not limited to, production of a seed bank to take advantage of sporadically favorable hydrologic conditions (van der Valk 1981, Casanova and Brock 2000), malleable morphology under different hydrologic regimes (Miller and Zedler 2003), or regeneration through asexual vegetative propagation (Combroux et al. 2002, Combroux and Bornette 2004). 
Topographic patterning in wetlands can arise from interactions between living plants and partially decayed vegetation, known as peat (Foster et al. 1983, Eppinga et al. 2008, 2010), forming the soil base for many wetland plant species. Complexity in topographic patterning can be derived from spatially variable differences in both peat accretion and decomposition that sustain and are sustained by microhabitat differences in resource limitation (Belyea and Clymo 2001, van Wesenbeeck et al. 2008, Watts et al. 2010, Eppinga et al. 2010). Spatial variation may particularly arise in wetlands with long hydroperiods and acidic $\mathrm{pH}$, where non-living organic biomass readily accumulates and contributes to the soil building (Clymo 1984, Smith et al. 1993, Belyea and Clymo 2001). Furthermore, in wetlands with distinct vegetation patches, topographic relief (and therefore localized water depth) can vary considerably over small horizontal distances (Kirkman et al. 1998, Larsen et al. 2007), despite a level water surface (as it is constrained by gravity). As the hydrologic regime is modified, imbalances occur in the equilibrium between peat accretion and aerobic respiration, because changes in these processes with respect to water depth are non-linear (Cohen et al. 2011, Heffernan et al. 2013). For example, lowering water depth increases both peat accretion, through primary production, and aerobic respiration, through increasing microbial activity and $\mathrm{CO}_{2}$ emissions to the atmosphere, but the rates of these processes are different at varying water depths. The resulting imbalances in the accretion-respiration equilibrium can transition landscapes with complex plant communities and topographic patterning to landscapes that are more vegetatively and topographically homogeneous (Eppinga et al. 2007, Watts et al. 2010). Furthermore, transitions may occur rapidly through a transition between multiple alternative stable states in a positive accretion-respiration feedback loop (Chase 2003, Eppinga et al. 2007). 
As with many ecosystems world-wide, wetlands are experiencing considerable changes. In particular, land use and climactic changes are altering the timing and severity of disturbances, often with catastrophic effects on wetland vegetation communities such as loss of total extent, changes in vegetation assemblages, invasive species and disruptions to ecological patterning and functionality (Mitsch and Gosselink 2000, Zedler and Kercher 2004, Eppinga et al. 2007). In the present study, my overall objective is to further understanding of the effects of hydrologic regime modification on vegetation community patterning. The Florida Everglades' distinct vegetative and topographic patterning and variable hydrologic regimes make it an excellent system to understand the interactions among vegetation, topography and hydrologic regimes that are common to many wetlands, and, more broadly, how such interactions depend on and influence the spatial patterning of ecological communities.

\section{The Florida Everglades}

\section{Background and history}

The Florida Everglades, located in southern Florida, USA, is a large subtropical wetland with diverse hydrologic, vegetative, and edaphic characteristics. Historically, a significant portion of this system was a slow, meandering river originating in the Kissimmee River floodplain, flowing into the large and shallow Lake Okeechobee, draining south and then southwest over extensive and highly oligotrophic peatlands into Florida Bay (Gaiser et al. 2004, McVoy et al. 2011). The subtropical Everglades peatland emerged 5-6,000 years ago with rising sea levels trapping freshwater flowing southward over a limestone bedrock platform 160 kilometres long and 50 kilometres wide into Florida Bay, at a near uniform descent totalling only about six vertical meters (Stephens 
1956, Gleason and Stone 1994, McVoy et al. 2011). Vegetation quickly colonized the submerged landscape, and peat, without sufficient aerobic respiration to oxidize, accumulated on the bedrock up to over $3 \mathrm{~m}$ (Gleason and Stone 1994). However, human-induced alterations to the hydrologic regime, including reduction, stabilization, and impoundment of water through diversion and compartmentalization via canals, levees and roads, have degraded both pre-drainage vegetation community patterning and the underlying variation in topographic relief (Davis and Ogden 1994, Ogden 2005, Watts et al. 2010, McVoy et al. 2011).

Widespread recognition by the public on the effect changes to the hydrologic regime was having on the Everglades landscapes was inspired by Marjory Stoneman Douglas' influential book The Everglades: River of Grass (Douglas 1947), which borrowed its name from both the Everglades' subtle but important riverine characteristics and the extensive stands of sawgrass (Cladium jamaicense) that grow only 1-2 $\mathrm{m}$ above the water surface across the entire landscape-a characteristic thought to have prevailed for approximately the last 1,000 years (Bernhardt and Willard 2009). Douglas' illustration that the Everglades was not a simple swamp, but more a river, inspired of much greater public awareness that the Everglades had intrinsic value that warranted intensive hydrologic regime management and restoration efforts. An early result of this awareness was the formation of the Everglades National Park at the end of the same year. Despite River of Grass increasing public awareness of the need for Everglades restoration, the phrase has left an impression that the Everglades is a relatively homogeneous (but flowing) grassy marsh-and does not entirely convey the ecosystem's spatially diverse and complex vegetative and topographic characteristics (Richardson 2010).

Eight major landscapes occupied the historic pre-drainage greater Everglades (roughly from north to south): Custard Apple Swamp, Sawgrass Plains, Ridge and 
Slough, Peat Transverse Glades, Rockland Marl Marsh, Marl Transverse Glades, Perrine Marl Marsh, and the Ochopee Marl Marsh (McVoy et al. 2011). Of these, the Ridge and Slough landscape covered approximately $6,000 \mathrm{~km}^{2}$; over $50 \%$ of the total spatial extent of the Everglades (about $11,000 \mathrm{~km}^{2}$ ). Prior to hydrologic regime modification, the Ridge and Slough landscape was composed of abrupt shifts in topographic relief organized in a regular 'corrugated' pattern at distinct intervals parallel to water flow (Figure 1). Ridges, comprised almost—but not quite-entirely of dense stands of sawgrass, were located in areas of higher topographic relief, and therefore lower localized water depths, whereas sloughs containing white water lily (Nymphaea odorata), bladderworts (Utricularia spp.), and other macrophytes were at lower elevation and, therefore, deeper localized water depths (Loveless 1959, Ogden 2005, McVoy et al. 2011). A third community, the wet prairie, was comprised of spikerush (Eleocharis cellulosa), maidencane (Panicum hemitomon), beakrush (Rhynchospora tracyi), and other emergent plants in areas of intermediate water depths, usually occupying the area near the boundaries between adjacent ridges and sloughs (Loveless 1959, Ogden 2005). However, the permanent presence of the wet prairie community in the predrainage landscape, particularly at densities currently found, is disputed (McVoy et al. 2011). The Ridge and Slough landscape was also to a much lesser spatial extent interspersed with higher elevation tree islands that contained hardwood plant communities with areas that remained fully emergent throughout the year (Loveless 1959, Sklar and Valk 2002, Ross and Sah 2011).

\section{Vegetation community changes}

Vegetation communities in the Everglades, as in most wetlands, are restricted to a relatively narrow range of elevations determined by the hydrologic regime (White 1994, 
Ross et al. 2003, Armentano et al. 2006). The hydrologic regime is the most significant factor affecting the distribution, composition, shape and size of vegetation patches across the Everglades landscape (Gunderson 1994, Busch et al. 1998, Sklar et al. 1999, Ross et al. 2003, Armentano et al. 2006, Zweig and Kitchens 2008, Todd et al. 2010, Nungesser 2011, Foti et al. 2012, Sah et al. 2013). Furthermore, stress exerted by the hydrologic regime is thought to create and maintain ridge and slough communities, as well as distinct ecological boundaries (Larsen et al. 2007, Givnish et al. 2008, Watts et al. 2010, Cohen et al. 2011, Foti et al. 2013, Heffernan et al. 2013). Vegetation production, which is ultimate source of the organic matter in peat, and aerobic respiration, which consumes that organic material, are also influenced by hydrologic regime modification (SCT 2003, Zweig and Kitchens 2009, Larsen and Harvey 2010, D'Odorico et al. 2011, Cohen et al. 2011). Ridges accumulate biomass faster than sloughs (Childers et al. 2006), but, because water depths are lower and hydroperiods are shorter on ridges, aerobic respiration rates are also higher (Larsen and Harvey 2010, Cohen et al. 2011). Over long time scales, the production-respiration equilibrium is regulated at equal rates within both ridges and sloughs, limiting the difference in elevation between the two patch types. Therefore, the production-respiration equilibrium also create and maintain topographic variation, although the specific mechanisms of topographic creation, maintenance and degradation remain a matter of debate (Larsen et al. 2007, Cheng et al. 2011, Cohen et al. 2011, Kaplan et al. 2012, Heffernan et al. 2013).

Beginning in the early 20th century, widespread anthropogenic modification of hydrologic regimes has altered vegetation patch patterning and composition in the Ridge and Slough landscape (Davis et al. 1994, Fennema et al. 1994, Gunderson 1994, Light and Dineen 1994, SCT 2003, Ogden 2005, Nungesser 2011, McVoy et al. 2011). 
Average water levels across the Ridge and Slough landscape are estimated to have been 30-45 cm lower in 1955 than during between the pre-drainage era; although, water levels have rebounded in some areas since then, partially through concentrated restoration efforts (McVoy et al. 2011). Currently, sloughs frequently "dry-down" by the end of the dry season, but in the pre-drainage Ridge and Slough landscape sloughs are believed to have dried very rarely (McVoy et al. 2011). Shorter hydroperiods have significantly restricted the range and abundance of particularly slough species such as the historically ubiquitous white water lily and the even more hydrologically constrained spatterdock (Nuphar advena); a species adapted to the deepest water depths (McVoy et al. 2011). Lower water depths over sustained periods have, alternatively, led to range expansion in species that are better adapted to lower water levels, such as sawgrass (Urban et al. 1993, Davis and Ogden 1994, Gunderson 2001). Ridges have invaded slough areas (SCT 2003, Ogden 2005), and much of the slough landscape, particularly in Everglades National Park, has been usurped by wet prairies and ridges (Davis et al. 1994, Olmsted and Armentano 1997, Busch et al. 1998). Similarly, woody vegetation likely did not inhabit the ridge community prior to hydrologic regime modification (McVoy et al. 2011), but wax myrtle (Myrica cerifera) and coastal plain willow (Salix caroliniana) frequently inhabit the core of ridge communities in drained areas (Loveless 1959, McVoy et al. 2011).

Although Everglades' vegetation across the Ridge and Slough landscape is strongly regulated by the hydrologic regime, other environmental drivers of vegetation community changes may operate independently or in concert with hydrologic regime modification. For example, increased nutrient concentrations are an important driver of vegetation patterns in areas of the Ridge and Slough landscape, in part caused by the proliferation of southern cattail (Typha domingensis), which outcompetes sawgrass communities in 
areas with high phosphorus concentrations and adequate water depths (Urban et al. 1993, Craft et al. 1995, Newman et al. 1996, Daoust and Childers 2004). However, phosphorus is quickly taken up by organisms and the extent of the influence of phosphorus enrichment, while penetrating several kilometers into the protected areas of Everglades National Park, is localized compared to the total extent of the Ridge and Slough landscape (Childers et al. 2003). Fire events are common in the Everglades, but damage to non-woody vegetation is limited mostly to above the water surface, and its direct effects on vegetation communities in the Ridge and Slough landscape are likely negligible (Herndon et al. 1991, Beckage et al. 2003, Larsen et al. 2011). However, the influence of fires burning living organic matter on soil accumulation and the interactive effects of hydrologic regime modification and fire events warrant further research (Lockwood et al. 2003). Muck fires (peat fires) can burn peat to 10-20 cm deep when dry, and may exert considerable stress on vegetation patches over long timescales (Sklar and Valk 2002), such as causing succession of sawgrass dominated ridges into wet prairies and sloughs (Gunderson 1994). Although the direct impact of muck fires is likely relatively localized, the spatial propagation of vegetation succession following muck fire damage also merits future research. Finally, the effects of hurricanes and moisture redistribution during infrequent and stochastic events driving vegetation patterns in the Ridge and Slough landscape remains understudied.

\section{Vegetation community and topographic variation loss}

The distinct ecological boundaries between vegetation communities that were a defining feature of the pre-drainage Ridge and Slough landscape are dependent on the maintenance of abrupt topographic relief, which is itself affected by hydrologic regime modification (Larsen et al. 2007, Watts et al. 2010). Hydrologic regime modification 
therefore affects both topographic variation and vegetation community patterning (because vegetation communities are strongly dependent on the local long-term water depths and hydroperiods), sometime after an initial perturbation (Ross et al. 2003, Givnish et al. 2008, Zweig and Kitchens 2009, Watts et al. 2010). However, neither the relative nor absolute timescales of the interrelated vegetation patterning and topographic variation changes are well understood. Ross et al. (2003) found that vegetation communities in the hydrologically diverse Shark Slough, ENP correlated to localized water depth, but that after hydrologic regime modification vegetation communities lost association to their absolute water depths. The authors suggest that long-term loss of connectivity might be caused by vegetation response lags after changing hydrologic conditions, possibly in combination with increasing fire regimes affecting sawgrass succession at higher elevations. Givnish et al. (2008) determined that vegetation communities across a hydrologic gradient responded predictably to long-term water depths, but that the absolute water depths among basins supporting the same vegetation communities were significantly different, indicating that temporal lags in vegetation responses to hydrologic changes may be significant and over extended timeframes. Watts et al. (2010) hypothesized that topographic variation changes occur more rapidly than changes in vegetation communities after hydrologic regime modification. They argued that drainage and stabilization of the hydrologic regime led to rapid peat loss through aerobic bacterial respiration in higher elevation ridges compared to sloughs, leading to flattening of landscape-scale topography. Simultaneously, but over significantly longer timescales, drained and stabilized hydrologic regimes facilitate ridge expansion through drained sloughs, eventually homogenizing vegetation patches across landscapes. Shifts in vegetation communities and topography from heterogeneous to homogeneous landscapes were hypothesized to occur through a relatively rapid 
transition between the two stable states (Watts et al. 2010, Cohen et al. 2011, Heffernan et al. 2013).

\section{Vegetation communities and leading indicators of ecological change}

Some plant species in the Everglades are more resistant to changing hydrologic regimes than others because of differences among species in biomass storage, maturation, regeneration intervals, and fecundity. Specific sets of species therefore may be particularly useful as leading indicators of environmental change. Possible leading indicators of change through analysis of differences among species in the Everglades include work by Zweig and Kitchens $(2008,2009)$ who found that vegetation groups within broader community types assigned in to one of several different categories based on species composition responded to changing hydrologic regimes at different rates as a consequence of different life-history strategies. Similarly, groups of species that have a very short turnover time, such as the microbial organisms comprising periphyton communities, have been suggested as appropriate early indicators of change because they react quickly to relatively small environmental fluctuations (Gottlieb et al. 2006, Gaiser 2009, Gaiser et al. 2013). At the landscape scale, Wu et al. (2006) established that ridge patterning changed in response to modified hydrologic regimes at variable rates through time, suggesting that changes in ridge patterning itself could be useful as a leading indicator in predicting community changes. Detection of rapid and potentially catastrophic environmental changes in the Everglades are mostly concentrated on specific species, localized patches of communities, distinct groups of species, or, alternatively, landscape-level processes. In this respect, analyses of changes in vegetation community composition within a wider landscape as a useful leading indicator of catastrophic ecosystem changes are currently underdeveloped. 
The relative timescales of vegetation-topographic variation loss and how long these interrelated changes occur after an initial perturbation to the hydrologic regime is not well understood. Increased knowledge of the concomitant vegetation-topography changes would be an important step towards describing the processes that drive vegetation and topographic degradation and restoration, and could help Everglades' environmental managers assess leading indicators of ecosystem changes.

\section{Objectives and approach}

The primary goal of this study is to further understanding of changes in vegetation community distinctness caused by hydrologic modification using species compositional differences within and among different landscape blocks across a hydrologic regime gradient. These issues are addressed in two questions:

1. How is vegetation community distinctness affected by topographic variation and hydrologic regime changes in the contemporary Everglades Ridge and Slough landscape?

2. What are the relative timescales of vegetation and topographic variation change in the contemporary Everglades Ridge and Slough landscape?

I address these questions using spatially extensive and intensive descriptors of vegetation community composition and their relationships to topography and, ultimately, the hydrologic regime. I assess differences in vegetation community distinctness by measuring the segregation of species composition among patches. A spatial measure of variable hydrologic regimes is used as a proxy for changes through time. Concomitant 
topographic variation differences are also measured in order to assess the relative timescales of vegetation and topographic changes after hydrologic regime modification.

\section{Methods}

\section{Sampling design and implementation}

My study takes advantage of a previously established framework for representative sampling over a large portion of several historic Everglades landscapes. A Generalized Random-Tessellation Stratified sampling design (GRTS; Stevens and Olsen 2004) was used to arrange the Everglades landscapes into a grid of $2 \times 5 \mathrm{~km}$ landscape blocks (hereafter referred to as primary sampling units [PSUs]), with the $5 \mathrm{~km}$ edge of each PSU aligned parallel to the historic water flow. A spatially-stratified random sample of 80 PSUs was selected for sampling over a five year period ( $n=16$ per year), with each yearly draw also representing a spatially balanced sample of all of the modern Everglades basins (Everglades National Park (ENP), Loxahatchee National Wildlife Refuge (LNWR), Water Conservation Area 2 (WCA 2), Water Conservation Area 3A South (WCA 3A S), Water Conservation Area 3A North (WCA 3A N), and Water Conservation Area 3B (WCA 3B); Figure 2).

Data for this study were taken from 27 PSUs (from sampling years 1 and 2) that were located inside the historic distribution of the Ridge and Slough landscape (McVoy et al. 2011). Four additional PSUs located outside of the historic Ridge and Slough landscape were sampled but not analyzed in the current study. One PSU was physically inaccessible for sampling (because of dense cattail overgrowth): PSU 5, located at the northern boundary of WCA 2 . The 27 PSUs ultimately included in this study captured a wide range of contemporary hydrologic regimes within the historic boundaries of the 
Everglades Ridge and Slough landscape, with vegetation communities and topographic variation covering all major basins, from well-conserved to severely degraded (Wu et al. 2006, Givnish et al. 2008, Watts et al. 2010, Nungesser 2011).

Each PSU contained 80 sampling nodes in a spatially-stratified design. The PSUs were divided in to a grid (each of the sixteen grid cells within a PSU being $1.25 \mathrm{~km}$ by $500 \mathrm{~m}$ ), with 5 nodes randomly distributed within each grid cell. Each node contained three sampling points; a central sampling point, and two sampling points parallel and perpendicular to the long axis of the PSU and the historic direction of the water flow (to the north and east respectively) at random distances between 3 and 35 meters - a total of 240 sampling points for each PSU. For PSUs within ENP, access, which was usually by helicopter and foot, restricted sampling to 135 sampling points. GPS coordinates were calculated on a computer beforehand and then located in the field using a Garmin GPS 72 navigator (precision: $\pm 3 \mathrm{~m}$ ). Field sampling was conducted in 2010 and continued in 2011 largely during the Everglades' wet season between the months of July and December to maximize the number of sampling points with water above the soil surface. At each sampling points, all plants within a $1 \mathrm{~m}^{2}$ quadrat were identified to species level, and plant and periphyton densities were estimated as the percentage cover of the sampling area at $1 \%, 5 \%$ or $10 \%$ intervals thereafter.

Each sampling point was also designated in the field to categorical vegetation community types (for example; ridge, slough, wet prairie), or mixed communities (for sampling points that were ambiguous, such as the ridge/slough mix) based on a visual inspection of the species within the quadrat. The water depth was measured using a meter ruler with a $10 \mathrm{~cm}$ diameter foot and was defined as the distance from the peat surface at the center of the quadrat to the water surface. 


\section{Estimation of local hydrologic regime}

The US Geological Survey's Everglades Depth Estimation Network (EDEN) records water stage data daily from 253 stations at a grid size of $400 \mathrm{~m}^{2}$. The height of the water surface at any geographic point can be calculated through interpolation of water stage data collected by several nearby stations (Pearlstine et al. 2007). The accuracy of both the EDEN network's stage data and its interpolation was independently validated in Liu et al. (2009). Statistical measures relating to the water depth over several years provide a more accurate representation of the temporal hydrologic fluxes compared to the field measurements at time of sampling, which provide only a "snapshot" of daily and seasonally dynamic hydrologic conditions. However, more precise local water depth measurements do allow improved estimates of elevation, and thus long-term hydrologic conditions, as compared to the coarse resolution of the soil elevation map $\left(400 \mathrm{~m}^{2}\right.$ pixels) used by EDEN to estimate water depths. By combining the temporal stage data from EDEN water surface height records and the measured water depth, we estimated the fluctuating water depth at each sampling point for the period of time EDEN water level recorders have been recording (direct measurements since October 1, 1999; hindcast data available back to January 1, 1991). From these, we calculated long-term mean water depth and inundation frequency (i.e., hydroperiod) for 20 years prior to the sampling date for each sampling point. The mean water depth for individual sampling points over the 20 year record was calculated by using the EDEN record to calculate the water surface height at each sampling point's geographic location on the sampling day, and taking away the measured water depth to calculate the elevation of the peat surface for each sampling point. Then, the peat surface elevation was taken away from the mean water surface height over the 20 year EDEN record, giving the mean water depth over the 20 year record at each sampling point. The mean water depth within each PSU 
over the 20 year EDEN record was calculated by taking the mean of all within-PSU's sampling points' mean water depths over the 20 year EDEN record. The mean water depth over the 20 year EDEN record across PSUs represented, in this analysis, the hydrologic gradient across the Ridge and Slough landscape. Within each basin (ENP, WCA $3 A$ S, etc.), the mean and variation among PSUs in mean water depth over the 20 year EDEN record was calculated using the mean for all PSUs within each basin (shown in Figure 2).

\section{Analysis of Vegetation Composition and Distinctness}

Differences in the distinctness of vegetation community composition were assessed across the Ridge and Slough landscape to better understand the effects of hydrologic regime modification on vegetation patterning. Vegetation community composition distinctness was quantified using Kruskal's non-metric multidimensional scaling (NMDS; Kruskal 1964) ordination to partition sampling points within PSUs on the basis of species composition dissimilarity. I used local-scale (within-sampling points) associations to assess how vegetation community composition varied as a function of local hydrologic regimes. To describe distinctness of vegetation communities within each PSU, sampling points within each PSU were partitioned into two clusters, the distance between cluster centers providing the measure of vegetation community distinctness. I used the cluster distance proxy to assess the differences in distinctness among PSUs and its relation to topographic and ultimately hydrologic characteristics.

The distinctness of vegetation community composition (Question 1) was measured using clustering of sampling points within ordination space, with each sampling point containing a vector of species and their respective abundances. Distinctness was analyzed using NMDS ordination. In this analysis, a single "global" NMDS ordination was 
created that encompassed all PSUs in order both to obtain a global measurement of the clustering of sampling points-regardless of the environmental conditions-among all PSUs and to standardize all measures of dissimilarity within and among-PSUs.

All observations from sampling points within each PSU were separated from the global NMDS to characterize compositional patterns within PSUs. Observations from each PSU were coerced into two discrete clusters using k-means clustering. Two clusters were chosen in this analysis: (1) to simplify within-PSU distinctness measures; and (2) to best represent the presumed distinct communities associated with the overwhelmingly dominant ridge and slough communities in the historic pre-drainage landscape which, in this analysis, should occupy distinct regions of the NMDS ordination space (because distinct communities are theorized to be composed of distinct sets of species). Cluster calculations were run 25 times with random starts and the most appropriate clustering solution was used for this analysis. The likely most appropriate kmeans cluster positions are obtained from the minimization of the sum of squares distance for each sampling point to the Voronoi-derived cluster centers using a nearest neighbor algorithm. To calculate a test statistic of vegetation community distinctness, the sum of squares distance between the two cluster centers was calculated for each PSU, and divided by the number of sampling points to derive the mean sum of squares (which is independent of the number of within-PSU points sampled used in this analysis). Larger cluster distance values result from a greater distance between the two k-means derived cluster centers, and, at least hypothesized in this study, greater vegetation community composition distinctness (a two dimensional schematic diagram based on data from shown in Figure 3a). Conversely, smaller cluster distances (nearer cluster centers) indicated less distinct vegetation community composition, and therefore a more vegetatively homogeneous landscape (Figure 3b). The PSUs were hypothesized to 
display variation in vegetation community composition distinctness, decreasing with increasing disparity between the estimated pre-drainage hydrologic regime and the spatially variable contemporary hydrologic regimes.

The PSU cluster distances were related directly to the hydrologic regime using a vector of the 20 year mean water depth fitted to the NMDS ordination space, aligned in the direction where it explained the most amount of the variation in the individual sampling points' mean water depths (Kantvilas and Minchin 1989). While the method for arranging the vegetation site scores in the NMDS ordination plot is non-metric, the ordination space itself is metric (Euclidian), as well as the overlain hydrologic vector. In this analysis, the ordination space was rotated so that the 20 year hydrologic regime predictor variable became the new primary axis (hereafter referred to as the hydrologic axis). Since this rotation shifted sampling points within a PSU equally (the rotation was about the NMDS origin), cluster distances were unaffected. Rotating the NMDS ordination to the 20 year hydrologic axis not only enabled analyses on the basis of an ecologically meaningful variable (as opposed to a randomly generated rotation or a rotation to the largest principal component), it also enabled assessment of vegetation community patterns across a linear and regularly spaced axis (representing the 20 year hydrologic regime).

The relationship between cluster distance (as the measure of community distinctness) and the long-term hydrologic regime was analyzed to assess the effect hydrologic regime modification had on vegetation community distinctness across the Everglades Ridge and Slough landscape. Both drainage and impoundment influence landscape patterning and community composition (Ross et al. 2003, Wu et al. 2006, Givnish et al. 2008, Nungesser 2011, Sah et al. 2013), so it is therefore hypothesized that relationships between hydrologic conditions and vegetation community distinctness 
would be non-linear, with highest distinctness values at intermediate water levels. The Gaussian function (which was chosen over least-squares linear regression because of the hypothesized shape of the relationship between vegetation community distinctness and the hydrologic regime) was fitted to the vegetation distinctness measure based on the mean and standard deviation of the PSUs' hydrologic regimes over the 20 year hydrologic record.

To assess whether vegetation distinctness corresponded to the physical segregation of vegetation communities, the mean and variation of the three most frequently observed vegetation communities were compared across the hydrologic axis within the NMDS ordination space and related to the 20 year mean water depth. Because Everglades vegetation communities generally assemble on narrow hydrologically derived habitats (Loveless 1959, McVoy et al. 2011), communities were hypothesized to occupy distinct positions across the hydrologic axis. Furthermore, communities that are dominated by few species, such as ridges (which are dominated by sawgrass), are hypothesized to occupy a less variable hydrologic regime than others such as the myriad of species that constitute the slough community.

The premise in this analysis is that cluster distances correspond to distinct communities, but other patterns could also produce large cluster distances. For example, PSUs could be composed of a single high-variance cluster rather than two discrete clusters. To assess the correspondence of cluster distance and distinctness, PSU-scale vegetation community distinctness was examined over the hydrologic gradient using site scores based on the NMDS ordination rotated to the 20 year hydrologic axis. The PSUs with larger cluster distances were assessed for the presence of distinct clustering (i.e., a bimodal distribution along the primary hydrologic axis) which were hypothesized to represent dominance by distinct ridge and slough communities. In 
PSUs with shorter cluster distances, I expected that bimodality would degrade. In other words, two clusters should be apparent in more vegetatively distinct PSUs if species composition within these PSUs is strongly partitioned to hydrologically derived habitats.

To test whether the k-means cluster analysis partitioned communities, a global kmeans analysis using two clusters was compared to the field designated vegetation communities along the hydrologic gradient. A global k-means analysis was chosen preferentially over summing the individual k-means analyses used for the cluster distance analyses as there was no expectation that vegetatively indistinct PSUs would partition into discrete communities. An odds ratio test was used to quantitatively assess how likely a given cluster was to appear in a particular community, as it revealed how strongly the k-means clustering technique segregated the field designated vegetation communities.

A second approach to confirm that k-means derived clusters corresponded to ridges and sloughs in relatively distinct PSUs assessed the differences in abundance of a dominant species between the two clusters within each PSU. Sawgrass (Cladium jamaicense) was chosen because it is overwhelmingly dominant in ridges and relatively rare in sloughs, the two most spatially extensive vegetation community types, and it is currently ubiquitous in the Ridge and Slough landscape. Within each PSU, the mean sawgrass percentage cover for each k-means derived cluster in the NMDS ordination space was calculated. The PSUs were ranked according to their hydrologic regimes (mean water depth over 20 years), to facilitate understanding of how sawgrass partitioned within and among PSUs across the hydrologic gradient. Distinct vegetation communities within PSUs were hypothesized to segregate strongly between clusters, with one cluster containing a high abundance of sawgrass (corresponding to ridges) and the other a low abundance of sawgrass (sloughs). Furthermore, k-means clustering was 
hypothesized to not partition well in vegetatively degraded PSUs, because they are either frequently dominated by a single community type or there is more mixing of species among communities. Very dry or very wet PSUs over the 20 year hydrologic record should be reflected by absolute sawgrass abundances, where drier PSUs have more total sawgrass and wet PSUs, less, corresponding to sawgrass' competitiveness in drier landscapes.

The relationship between vegetation community distinctness and a quantified measure of topographic variation was evaluated to further understanding of the relative timescales of changes across the Ridge and Slough landscape. Topographic variation within each PSU was calculated using the standard deviation of elevations (or measured water depths). To assess the relative rates of vegetation community distinctness and topographic variation changes (Question 2), the relationship between cluster distance and within-PSU topographic variation was assessed by simple least-squares linear regression. The relationship between vegetation community distinctness and topographic variation was also used to assess the relative time scales over which vegetation and topography degrade. If vegetation was found to degrade first, then PSUs with indistinct communities but large topographic variation would be observed; conversely, if topography was found to degrade before vegetation, then the expected observation would be PSUs with distinct vegetation communities but little topographic variation. To evaluate these predictions, vegetation community distinctness and topographic variation by PSU were categorized based on the position of a local minimum across a gradient of each measure's value. The local minimum was reasoned to represent a relatively rapid transition in both vegetation community distinctness and topographic variation. Relative timescales of change were evaluated using a quadrant system, with each quadrant relating to the four possible states of conserved or degraded 
community distinctness and topographic variation based on the local minimum (schematic diagram shown in Figure 4). The quadrant system is therefore also a measure of PSU-scale ecological condition. Vegetation community changes were likely influenced by topographic variation changes if significantly more PSUs were located in the conserved vegetation-degraded topography quadrant, and vice versa.

Three measures to evaluate the relationship between elevation and vegetation community composition within each PSU were created. Each measure tested the hypothesis that the association between vegetation communities and topographic variation decreased with long-term hydrologic regime modification at both the wettest and the driest extremes of the hydrologic gradient. The first measure used was the difference in water depth between k-means derived clusters, which was calculated by taking the difference in the mean of water depths (as a proxy for elevation) over the 20 year record for all sampling points within each cluster constituting a PSU. The k-means difference in mean water depth therefore provides a statistic that is directly derived from the vegetation community composition distinctness (cluster distance) and topographic variation (with water depth as the proxy) analyses. The second measure was the correlation between each sampling point's sawgrass abundance and the mean water depth over 20 years within each PSU, analyzed using least-squares regression. Sawgrass' correlation to water depth was included because sawgrass abundance is a relatively simple metric to quantify for Everglades' environmental managers and leastsquares regression is a relatively concise and commonly used statistical technique. The third measure utilized the Mantel test (Fortin et al. 2002) to provide a metric of the correlation between vegetation community composition and 20 year mean water depth. The Mantel test was used in this analysis because the technique compares actual 
vegetation community composition and related topographic elevation as a commonly used ecological multivariate analytical method.

These five indices: k-means difference in water depth, sawgrass correlation to water depth, Mantel test, vegetation community distinctness and topographic variation, were mapped on to the Everglades Ridge and Slough landscape to assess the spatial patterns of landscape condition. A sixth map, derived from the categorical community distinctness-topography quadrants, shows the PSUs that are vegetatively and topographically conserved, degraded or in a transitional state based on the vegetationtopography quadrant system of landscape condition.

\section{Software}

All analyses and visualizations were performed using $R$ (version 2.15.2; $R$ Development Core Team 2011), except the vegetation-topography quadrant graphic (Figure 4), which was created using Inkscape (version 0.48; www.inkscape.org). The global NMDS ordination was created using the metaMDS function in the vegan package (version 2.0-5; Oksanen et al. 2005). The default convergence criterion in monoMDS (the engine metaMDS uses to produce random starting points) was too slack to find a convergent solution and was therefore tightened (but is now the default criterion as of vegan 2.0-6). The dissimilarity matrix for the NMDS ordination was calculated using the vegdist function in vegan with the Jaccard index, which, as a metric index, was preferentially chosen for detecting the underlying metric hydrologic gradient over the semimetric Bray-Curtis. Fitting and rotating the NMDS to the 20 year hydrologic axis was completed using the enfit function in vegan. The Mantel test also used the Jaccard index for calculating the distance matrix for vegetation communities and the Euclidean index was used for the distance matrix for the mean water depth over 20 years vector. The k- 
means derived clusters were calculated using the $R$ base package stats ( $R$ Development Core Team 2011), and all maps were created using the base $R$ plotting functions ( $R$ Development Core Team 2011). All other figures were created using ggplot2 (version 0.9.1; Wickham 2008) and combined, where relevant, using lattice (version 0.20-24; Sarkar 2010) or Inkscape (www.inkscape.org).

\section{Results}

\section{Vegetation composition and distinctness}

Overall, 4,859 points were sampled and used in these analyses, including 2,570 ridge, 1,036 slough, and 593 wet prairie communities based on field designations. Seven different vegetation communities across the entire Everglades Ridge and Slough landscape were described, although, of these, only four communities had greater than 50 sampling points (ridge, slough, wet prairie and cattail). Eight different assemblages in the $1 \mathrm{~m}^{2}$ quadrats were characterized as not belonging to a single community type and labelled as one of the "mixed" communities (for example, a ridge/slough mix). Twentyseven additional sampling points were measured but were dry, and were removed prior to analysis because they would provide inaccurate long-term mean water depths. One sample was removed because of a water depth recording error. Four sampling points were removed because no plants were recorded, and would have prohibited the NMDS ordination calculation. Two sampling points were removed from the analysis and the NMDS ordination rerun because of the presence of cocoplum (Chrysobalanus icaco) at extreme water depths having an unduly large effect on the ordination calculation. A scree plot of the NMDS ordination suggested weakly that five dimensions would best represent the data, resulting in a stress value of $0.0835(8.35 \%)$. 
Species were largely limited to their field designated communities: sawgrass (Cladium jamaicense) was most abundant in ridges and then in the mixed ridge/slough and ridge/wet prairie communities; spikerush (Eleocharis spp.) were most abundant in wet prairies and slough-wet prairie mix; bladderworts (Utricularia spp.) and white water lily (Nymphaea odorata) were most abundant in sloughs and mixed slough communities; and cattail (Typha domingensis) was almost entirely contained within the cattail community (Figure 5). Periphyton was more cosmopolitan than any other component of the Everglades plant communities; it was abundant in all major community types in except the driest (tree island and mixed tree island) and likely the most eutrophic (cattail; see McCormick et al. 2008, Gaiser et al. 2011). Vegetation communities categorized by their field designation sorted along the 20 year mean water depth (Figure 6). For example, ridges were consistently at lower water depths than wet prairies which were, in turn, constantly drier than sloughs. The contemporary hydrologic regime varied among all Everglades basins: Water Conservation Area 3A North (WCA 3A N) had the highest 20 year mean water depth, but also the largest variance within all three of the most frequently sampled vegetation communities suggesting that it is the most hydrologically diverse basin (Figure 6). Loxahatchee National Wildlife Reserve (LNWR) had the lowest water depth over this period across all major vegetation communities. No wet prairie communities were observed in Water Conservation Area 2 (WCA 2), and only one in LNWR, whereas wet prairie communities were unusually abundant compared to sloughs in Everglades National Park (ENP). Water Conservation Area 3A South (WCA 3A S) had a proportionately higher percentage of sloughs compared to all other basins. Within each Everglades basin, the 20 year mean water depth decreased from sloughs to wet prairies (which were entirely absent in WCA 2), to ridges. However, communities did not equate hydrologically between basins; for example, the 157 sloughs in LNWR were at a lower 
20 year mean water depth $(24.3 \mathrm{~cm})$ than the mean water depth in the 2,240 ridges in every other basin (mean $=30.75 \mathrm{~cm}$; Figure 6).

The three most frequently observed vegetation communities segregated distinctly across the hydrologic axis (Figure 7). The ridge community was most frequently observed close to its median water depth, indicating that this community is relatively compositionally homogeneous, whereas sloughs and wet prairie communities displayed more variability across the hydrologic axis. In conserved PSUs with distinct community composition (large cluster distances), NMDS scores along the hydrologic vector were split clearly into two clusters (Figure 8). However, in more vegetatively degraded PSUs, the within-PSU NMDS site scores along the hydrologic axis were less bimodal and clusters were less distinct.

Within almost all PSUs, sawgrass abundances were weighted heavily towards a single cluster (Figure 9). However, the segregation of sawgrass between clusters was greatest in the most distinct PSUs (the green [or lighter] bars in Figure 9) with all PSUs containing at least $<20 \%$ in one cluster and $>60 \%$ in the other. Sawgrass segregation between clusters was still observed in the less distinct PSUs (the red [or darker] bars in Figure 9), but distributions and average sawgrass abundances were considerably less predictable than in more distinct PSUs.

The global k-means clustering analysis of vegetation communities correlated strongly to the mean water depth over 20 years (as a proxy for topographic elevation; Figure 10). A total of $81.3 \%$ field designated ridge communities were in Cluster 1 and $97.5 \%$ of sloughs were located in cluster 2 , along with $87.9 \%$ of wet prairie communities. Furthermore, the mean water depths for the three most frequently observed vegetation communities, the ridge, slough, and wet prairie, correlated with the mean water depths along the hydrologic axis (Figure 7). Mixed vegetation communities designated in the 
field were almost always located between their constituent communities, for example, mixed slough/wet prairie communities had a mean water depth, hydroperiod, and cluster ratios between that of the slough and the wet prairie communities. However, this was notably not the case for the relatively frequently observed ridge/slough mixed community which had on average marginally lower mean water depths than ridges. The odds ratio for the three community types based on the global k-means cluster analysis indicated that field designated ridges were 169 times more likely to be in cluster 1 than sloughs, and that wet prairies were more closely aligned to sloughs than ridges (odds ratio of 5.37 and 31.5, respectively; Figure 11).

\section{Hydrologic and topographic effects on distinctness}

Distinct communities, represented by cluster distance, were only observed across the 20 year hydrologic gradient between about $20-50 \mathrm{~cm}$ mean water depth (Figure 12). The PSUs near the hydrologic extremes, in both the wetter and the drier directions, contained only relatively indistinct communities. The PSUs in ENP, WCA 3A S and Water Conservation Area 3B (WCA 3B) clustered relatively closely on both the vegetation community distinctness and the 20 year mean water depth axes, whereas WCA 3A N's PSUs had both variable vegetation distinctness (i.e., between cluster distance) and high variability in 20 year mean water depth (containing both the two driest and three wettest PSUs along the hydrologic gradient). Three PSUs, all in northern WCA $3 \mathrm{~A} \mathrm{~N}$, contained more than $5 \%$ relative total cattail abundance as a percentage of the total vegetation cover (PSU 11 at 6.29\%; PSU 27 at 16.00\%; and PSU 19 at $20.57 \%$ ), which correlated to increased community composition distinctness (cluster distance $=$ $0.288,0.904$, and 0.689 , respectively). 
Vegetation community composition distinctness correlated with differences in topographic variation $\left(r^{2}=0.49, \operatorname{Pr}(>F)<0.001\right.$; Figure 13). Clustering of Everglades' basins in relation to topographic variability was also apparent; WCA 3A S displayed both distinct community composition and variable topography, whereas ENP, WCA 3B, and WCA 2 vegetation communities were generally less distinct and topographically homogeneous. LNWR and WCA 3A N basins were more variable.

Categorizing vegetation distinctness and topographic variation into conserved and degraded PSUs using the local minimum along each processes' gradient to assess the relative timescales of each process's changes resulted in seven PSUs in the conservedconserved quadrant, four of which were located in WCA 3A South (Figure 13). Thirteen PSUs were located in the degraded-degraded quadrant; these included five from WCA 3A North, all three WCA 3B PSUs and three of the PSUs in ENP. Seven PSUs were located in the conserved vegetation community distinctness-degraded topographic variation quadrant; these included the other three PSUs from ENP, the remaining two from WCA 3A S and one each from LNWR and WCA 3A N (Figure 13). No PSUs were situated in the degraded vegetation community distinctness-conserved topographic variation quadrant. Among PSU vegetation community distinctness binned by frequency of occurrence was bimodally shaped (Figure 14a); topographic variation was less bimodal than for vegetation community distinctness (Figure 14b), possibly because of a lack of topographically conserved PSUs in this analysis.

The three measures of vegetation-topographic correlation across the hydrologic gradient: k-means derived cluster mean water depth; sawgrass-water depth (WD) correlation $\left(r^{2}\right)$; and vegetation-WD Mantel $r$ score, respectively (Figures 15-17), all had high values in central portions of the hydrologic gradient, similar to those found in the pre-drainage Ridge and Slough landscape, and low values in both wetter and drier 
hydrologic extremes. Vegetation-topography correlations were again highest between about $20-50 \mathrm{~cm}$ mean water depth, and no large values were found at either the wettest or driest extremes of the hydrologic gradient.

Community distinctness for each PSU plotted on to a map of the Everglades showed that only a small portion of the Ridge and Slough landscape-notably central WCA 3A S-was in a relatively conserved condition, reminiscent of the pre-drainage landscape (Figure 18). The ENP, WCA 3A N, WCA 2 and LNWR were inconsistent, but WCA 3B's vegetation communities were consistently assessed as degraded. Topographic variation and the three measures of vegetation-topographic correlation mapped similarly to the vegetation community composition distinctness (Figures 19-22). Categorization of the conservation status for the combined vegetation community composition distinctness and topographic variability (from Figure 13 which was partitioned by the bimodality in both processes displayed in Figure 14a-14b) arranged on a map of the Everglades showed that only central WCA $3 A$ S was consistently in a relatively conserved vegetation and topographic state (Figure 23). Only three of the remaining 23 PSUs, one each in WCA $3 A$ N, WCA 2 and LNWR, were similarly conserved. All of WCA 3B and large areas of ENP and WCA 3A N had both degraded vegetation community distinctness and topographic variation. Seven PSUs across the Everglades Ridge and Slough landscape, including two PSUs in northern WCA 3A S and three in ENP, were categorized as containing distinct vegetation communities but having degraded topographic variation. No PSUs were categorized as vegetatively indistinct and topographically variable. 


\section{Discussion}

The results of this study show that degradation of vegetation community composition distinctness in the Everglades Ridge and Slough landscape is widespread, contrasting with the distinct vegetation communities that defined this landscape before significant human-induced modifications of the hydrologic regime began in the early $20^{\text {th }}$ century. Outside of the intermediate range of contemporary long-term hydrologic regimes observed in this study-in both the drier and wetter directions-distinct vegetation communities were absent. Differences in vegetation community composition distinctness and topographic variation in this study were correlated across the hydrologic gradient. Despite being highly coupled, vegetation community composition changes likely lag behind those in topographic variability, based on the prevalence of PSUs which possessed distinct community composition and homogeneous topographic relief and the absence of PSUs with the opposite configuration. The occurrence of degraded vegetation communities approximately within the range of long-term mean water depths that also support distinct communities may reflect decadal-scale lags in vegetation responses to changes in hydrologic regime restoration; however, it cannot be discounted that degraded landscapes reside within a vegetatively and topographically homogeneous alternative stable state, constrained by a large or possibly even impassable threshold in hydrologic conditions, which prevent vegetation pattern restoration (see Larsen et al. 2007, Cohen et al. 2011, Heffernan et al. 2013).

\section{Vegetation community distinctness in the Ridge and Slough landscape}

The quantitative measures of landscape-scale community composition distinctness strongly suggest that much of the vegetation community patterning that was a feature of 
the pre-drainage Ridge and Slough landscape has been lost. All basins in the Everglades Ridge and Slough landscape displayed extensive vegetation community degradation, with the notable exception of central Water Conservation Area 3A South (WCA 3A S), which contained relatively conserved (i.e. distinct) vegetation communities (Figure 18). Direct comparisons of community distinctness between the pre-drainage and the contemporary landscapes assessed in this study are precluded by the limited quantitative data on historical vegetation community patterning. However, what is certain is that the pre-drainage landscape was dominated by stands of sawgrass in ridge communities that strikingly contrasted with the surrounding more open sloughs. Vegetation community composition distinctness in the historic pre-drainage Everglades landscape would likely have been high, particularly if, as asserted by (McVoy et al. 2011), wet prairie communities were less frequent and less densely populated by several wet prairie species such as spikerush (Eleocharis cellulosa) and maidencane (Panicum hemitomon) that were commonly found in this study (Figures 5 and 10). Even the most conserved basin in this study, central WCA 3A S, contained a high abundance of the wet prairie community (Figure 6). Therefore, although portions of central WCA 3A $S$ have likely the most similar vegetation community patterning to the pre-drainage Ridge and Slough landscape based on findings in this research, central WCA 3A S abundant, dense and persistent wet prairie communities mean that even it likely displays some amount of degraded vegetative patterning compared to what the area historically exhibited.

Several patterns assessed in this study support the assertion that shorter cluster distances reflect vegetation community degradation based on loss of compositional distinctness in the Ridge and Slough landscape. For example, in the global k-means cluster analysis, sets of species partitioned strongly within field designated communities 
(Figure 5). Ridges were found to be dominated by sawgrass, whereas wet prairies and sloughs shared more similar species and were more cosmopolitan. Differences in distinctness between ridges and sloughs as an indicator of vegetation community change is supported by distinctness measures based on the k-means derived clustering of sawgrass abundances (Figure 9). In more conserved PSUs, sawgrass abundances were consistently well separated by cluster (with all of the more conserved PSUs containing at least $<20 \%$ in one cluster and $>60 \%$ in the other). Ridges and sloughs broadly occupy the two end members of the NMDS ordination gradient, with the wet prairie community occupying a more central portion (Figure 7). Similarly, ridge communities were considerably more likely to be in a particular cluster over the slough community and, again, the wet prairie community was more divided among clusters (Figure 11). In addition, differences among PSUs related to the loss of bimodal clustering as distinctness decreased (Figure 8). Given that this bimodality is based on dominance by the ridge community at one end of the gradient and the slough community at the other (see Figure 7), degradation of bimodality (and therefore distinctness) is based on the loss of either ridge or slough communities and the proliferation of centrally positioned wet prairie or mixed communities. The loss of vegetation distinctness among PSUs is therefore likely to be mostly influenced by pattern degradation among ridge and slough communities, the proliferation of communities that occupy a more central portion of the hydrologic gradient, or possibly the mixing of species beyond historic locations.

Unlike slough communities, cattail communities are able to form dense and relatively uniform stands with substantial biomass, and therefore fill a different ecological role in the Everglades than slough communities. The cattail (Typha domingensis) species was found in significant quantities (> 5\% total relative abundance) in three PSUs, which may have increased cluster distance in those landscapes. Cattail may 
increase cluster distance, and therefore vegetation community distinctness, as it rapidly proliferates in areas that have been impacted by phosphorus enrichment, possibly either by encroachment into sloughs and usurping slough species in deeper waters or through outcompeting ridges in ridge-dominated areas. Cattail creates slough-like environments through aeration of soils from flow-through convection in the roots and rhizomes, resulting in deeper water conditions (Belanger et al. 1989, Urban et al. 1993). Because of the nature of this study's statistical analysis, the presence of significant quantities of cattail within PSUs likely results in similar clustering outputs to PSUs with high abundances of sloughs. Prolific cattail within PSUs is likely caused by eutrophication (McCormick et al. 2008, Gaiser et al. 2011), and should therefore be considered degraded, despite the likely increase in cluster distance. Therefore, in heavily eutrophic areas of the Ridge and Slough landscape, caution is advised is using community composition based cluster distance measures as the sole measure of landscape degradation.

Vegetation community distinctness and hydrologic regime modification

The results of this study suggest that distinct vegetation communities require hydrologic conditions similar to those believed to have existed in the pre-drainage Ridge and Slough landscape (Figure 12; McVoy et al. 2011). Distinct vegetation communities occurred almost entirely within the range of $20-50 \mathrm{~cm}$ long-term mean water depth (Figure 12). Assuming a steady yearly cycle between the two hydrologic extremes averaged across ridges and sloughs in the pre-drainage landscape-estimated at $6 \mathrm{~cm}$ for ridges and $67 \mathrm{~cm}$ for sloughs in McVoy et al. (2011) — the mean of $36.5 \mathrm{~cm}$ is roughly similar to the 20 year hydrologic regime of the most conserved vegetation communities 
in this analysis. In the extremes of the hydrologic regime gradient-near both the driest and the wettest conditions-vegetation community distinctness was consistently low.

This study relates the consequences of a temporally variable hydrologic regime on vegetation community composition distinctness using a space-for-time substitution. Vegetation community distinctness was found to react relatively predictably and negatively as the hydrologic regime departs further from the estimated pre-drainage regimes towards the extreme end-members of the hydrologic gradient (Figure 12). In this study, the spatial analysis is supported by previous works that relate the hydrologic regime to vegetation community changes through time. For example, Armentano et al. (2006) established that composition and patterning of vegetation communities responded rapidly and substantially to changing hydrologic conditions over a 24 year period in Taylor Slough, ENP, but that vegetation communities did not always follow hydrologic regime changes. Busch et al. (1998) found that vegetation communities assessed over a decade associated predictably on hydrologically derived habitats and responded to hydrologic changes over a 40 year period. These time-based studies support the results of this spatially-focused study, showing that the distance between clusters is a faithful representation of vegetation community composition distinctness and that distinctness is negatively impacted with increasing hydrologic regime modification.

\section{Vegetation community distinctness and topographic variation}

In the Everglades Ridge and Slough landscape, as in all wetlands, topography acts as an intermediary between hydrologic processes exerting stress and the resultant vegetation community patterning (Figure 7, 9-10; van der Valk 1981, Mitsch and Gosselink 2000). Changes in topographic variation therefore affect vegetation patterning 
as species are forced to exist within hydrologically derived niche spaces that they did not previously, or species shift to a novel area that may or may not already be occupied by another species. The complex relationship that plants have with the hydrologic regime found in this study builds on the empirical research by Watts et al. (2010) and Givnish et al. (2008) and theory by Larsen et al. (2007), Cohen et al. (2011), Heffernan et al. (2013), and others, who have established that hydrologically drained as well as impounded landscapes resulted in reduced topographic variability in the Ridge and Slough landscape. As topographic variation is lost, vegetation community distinctness also decreases (Figure 13) indicating not only that vegetation-topography changes are closely coupled, but that their respective changes are both influenced by hydrologic regime modification (Watts et al. 2010, Cohen et al. 2011, Heffernan et al. 2013); Figure 12 and 13).

Vegetation and topographic response lags

Variation in water depths among Everglades' basins and associated differences in vegetation communities suggest the possibility of temporal lags in past and future vegetation responses to hydrologic modification (Figure 12). The high abundance of lower water depth wet prairie communities in place of sloughs in ENP compared to in WCA $3 A$ (Figure 12), as well as the dominance of the ridge community over all other community types in WCA 3B, despite both WCA 3B and ENP having similar long-term mean water depths to the more vegetatively conserved WCA 3A S (Figure 6), are both phenomenon indicative of temporal response lags. Furthermore, habitat settlement by species to field derived communities was found to be consistent among basins even though the absolute long-term water depths were variable (Figure 6 and 10), indicating that responses by vegetation communities lag behind changes in hydrologic regimes. 
These results are congruous with the findings in Busch et al. (1998), Ross et al. (2003), Armentano et al. (2006) and others, who described closely coupled vegetation communities to hydrologically derived niche spaces. As hydrologic regime changes occur, at least a subset of communities or areas lost association to the local water depths. Differences in mean water depths among basins found in this study support the conclusions in Givnish et al. (2008): they found that vegetation communities across all Everglades basins arrange according to hydrologically derived habitats, but that the absolute water depths that vegetation communities occur in are basin dependent. For example, in this study, LNWR contained a similar proportion of ridge-wet prairie-slough communities to WCA $3 \mathrm{~A} \mathrm{~S}$, but the mean water depths over all communities were consistently about $20 \mathrm{~cm}$ lower over the 20 year hydrologic record (Figure 6).

Vegetation community responses to hydrologic regime changes necessarily occur sometime after an initial perturbation; however, the duration of response lags and how vegetation interacts with topography are landscape-dependent. Seven PSUs were found to have conserved vegetation community distinctness with degraded topographic variation (based on the quadrat system; Figure 14a and 14b), whereas no PSUs possessed the opposite configuration (Figure 13 and the Everglades map in Figure 23). This relationship between vegetation and topography across basins within the Ridge and Slough landscape indicate that, after hydrologic modification, changes in topographic variation may lead those changes in vegetation community distinctness. As water depth changes persist over relatively long timescales, the normally equalized rates of vegetation accretion and peat respiration become unbalanced. This unbalancing alters topographic variation at the landscape scale as peat accretion-respiration rates are nonlinear because water depths vary locally. In this study, vegetation communities are asserted to respond sometime after topographic variation changes, because vegetation 
responses occur only after amenable habitats arise with changes in water depth. For species that vegetatively propagate, such as sawgrass (Cladium jamaicense), the loss of topographic variation between adjacent patches facilitates this advancement because there is an effective blurring of habitats between adjacent patches. Species that access the seed bank, such as many wet prairie species, do not necessarily interact directly with an ecological boundary; however, hydrologic conditions must be favorable for them to propagate, survive, or outcompete other species in a new patch type. Ultimately, this study suggests that when species move beyond their historic positions, vegetation community distinctness reduces because different species move beyond their historic positions at different rates.

Among basins, conserved vegetation communities existed predominantly within a range of $20-50 \mathrm{~cm}$ mean water depth over the 20 year period assessed in this study (Figure 12). However, seven vegetatively degraded PSUs in the Everglades National Park (ENP) and Water Conservation Area 3B (WCA 3B) contained long-term hydrologic conditions similar to those in vegetatively conserved PSUs (Figure 12). Hydrologic management decisions in the 1940s through to the 1980s resulted in considerable drying in ENP (Light and Dineen 1994, Ross et al. 2003, Gunderson and Light 2006, Armentano et al. 2006), but possibly also WCA 3B as it borders ENP to the north. Reduced water levels in these basins in the 1930s through 1970s resulted in the establishment of two relatively intensive efforts to restore water levels towards predrainage hydrologic regimes with Florida Governor Bob Graham's “Save our Everglades" program, introduced in 1983-4, and the dissolution by the U.S. Congress of a Federal program that required considerable water storage in the Water Conservation Areas that hydrologically starved the downstream ENP (Light and Dineen 1994, Gunderson and Light 2006). These two programs were reinforced in 2000 with the 
unveiling of the Comprehensive Everglades Restoration Plan (CERP; McLean et al. 2002, Sklar et al. 2005). Other studies also confirm that the hydrologic regime pre-1991 in at least ENP were lower, such as Busch et al. (1998), Armentano et al. (2006), and Sah et al. (2013), with an increase in water levels only occurring relatively recently, within the range of the EDEN water surface height records (about 20 years). Therefore, vegetation communities in ENP and WCA 3B that are currently vegetatively degraded may not yet have noticeably responded to hydrologic regime restoration efforts that were restored to a reasonable degree over 20 years ago. Neither the PSUs in ENP nor WCA 3B were found to have any significant abundance of cattail, indicating that cattail prevalence likely does not conflate community distinctness measures as has probably occurred elsewhere in the Ridge and Slough landscape.

Vegetation community distinctness responses to restoration of hydrologic regimes probably respond significantly at the landscape scale at timescales beyond 20 years, if they occur at all. Despite improvements in hydrologic regimes to approximately predrainage levels over the last 20 years, vegetation communities in most notably ENP and WCA 3B still have not recovered to a vegetatively distinct or patterned landscape. Although vegetation recovery lags are possibly 20 years or more behind sampling dates in this analysis, the long history of lower water depths in these landscapes from the beginning of the $20^{\text {th }}$ century indicate that it is possible that vegetation community response lags are considerably longer than this. Previous studies addressing lags have found similar, but not as extreme, timescales of vegetation responses. For example, Zweig and Kitchens (2008) determined that vegetation communities in southern WCA 3A are influenced considerably by both the current and the historic hydrologic regimes. In addition, they found that vegetation responses to hydrologic regime modification varied among species; sawgrass and white water lily response times were about four years 
after an initial hydrologic regime modification event, while species such as Utricularia spp. responded considerably quicker. Ross et al. (2003) established that vegetation communities did not always correspond to the measured hydrologic regime among sampling points, and concluded that this could be caused by lags in vegetation responses sometime after hydrologic regime modification, or possibly fire damage altering vegetation responses. Nungesser (2011) found that extreme "dry-downs" in the peat soil base could cause relatively rapid changes in vegetation community structure, but that in general vegetation

While lags in vegetation responses to hydrologic regime modification necessarily exist at least at some time-scale, whether vegetation community distinctness and topographic variability in ENP and WCA 3B are able to eventually exhibit vegetation community patterning similar to those found in the pre-drainage Ridge and Slough landscape at all is unknown. Vegetation communities and topographic variation have been hypothesized to occur as at least two alternative landscape states: the historic patterned Ridge and Slough landscape, and a vegetatively and topographically homogenous state (Larsen et al. 2007, Heffernan et al. 2013). Alternative stable states in vegetation community distinctness and topographic variation are supported to some extent by the relative dearth of PSUs in the transition zone between conserved and degraded PSUs (the troughs in Figure 14a and 14b), indicating that transitions from conserved to degraded vegetation patterns are likely rapid. If this is true, simply restoring historic hydrologic regimes that once maintain patterned landscapes to similar levels once found in the pre-drainage Ridge and Slough landscape will not necessarily result in vegetation pattern restoration, as discrete ecological thresholds beyond hydrologic conditions that maintain conserved vegetation communities would need to be breached (Larsen et al. 2007, Cohen et al. 2011, Heffernan et al. 2013). 


\section{Conclusions}

\section{Theoretical applications}

Future studies regarding vegetation community changes within patterned landscapes and other self-organized ecosystems may benefit from considering quantified fine-scale vegetation community composition differences as a measure of environmental degradation. The methodology in this study is a novel technique that is useful in reducing inherent dimensionality within empirical ecological community data to a meaningful test statistic that faithfully represents the observed ecological processes in at least predominantly binary systems (i.e., the domination by ridges and sloughs make the Ridge and Slough landscape at least in conserved areas predominantly binary). In this study, measurements of compositional differences facilitated analysis of subtle variation among local vegetation communities, as well as determination of differences among landscape blocks across an environmental gradient. Furthermore, complete measurements of species composition gave this study direct ecological relevance, and localized measures were easily relatable to the underlying fine-scale elevational gradients.

Partitioning of patterned landscapes based on the dominance of two distinct community types (the ridge and slough in this study) based on the distance between two defined clusters within an ordination space provides a novel method to assess vegetation pattern degradation. The use of NMDS ordination and k-means derived cluster distances is an effective methodology for future research relating the degradation of complex and patchy landscapes. Test statistics deriving metrics for both vegetation and topography allow direct comparisons between the relative rates of changes in response to environmental drivers. 


\section{Management implications}

Restoration of vegetation communities within landscapes has long been a goal of managers of the Everglades ecosystems (McLean et al. 2002, Sklar et al. 2005). This study helps identify the hydrologic regimes that permit and preclude the persistence of the Ridge and Slough landscape. Widespread areas of the Ridge and Slough landscape were found to be in a vegetatively degraded state. Vegetation community degradation is likely caused by alterations in the hydrologic regimes towards the extremes of the hydrologic gradient—both in the drier and wetter directions-more extreme than the regimes believed to have existed in the pre-drainage Ridge and Slough landscape. Differences in vegetation communities probably reflect changes in topographic variation, and, therefore, management of the underlying topographic relief deserves more attention. However, restoration of hydrologic regimes is unlikely to produce immediate results, as vegetation communities may lag behind hydrologic regime restoration, possibly for decades. In addition, understanding the role alternative stable state dynamics has in vegetation community changes in the Ridge and Slough landscape is critical, as thresholds in hydrologic restoration may prohibit restoration of compositionally and spatially distinct communities that dominated the pre-drainage Everglades. 


\section{Figures and Tables}

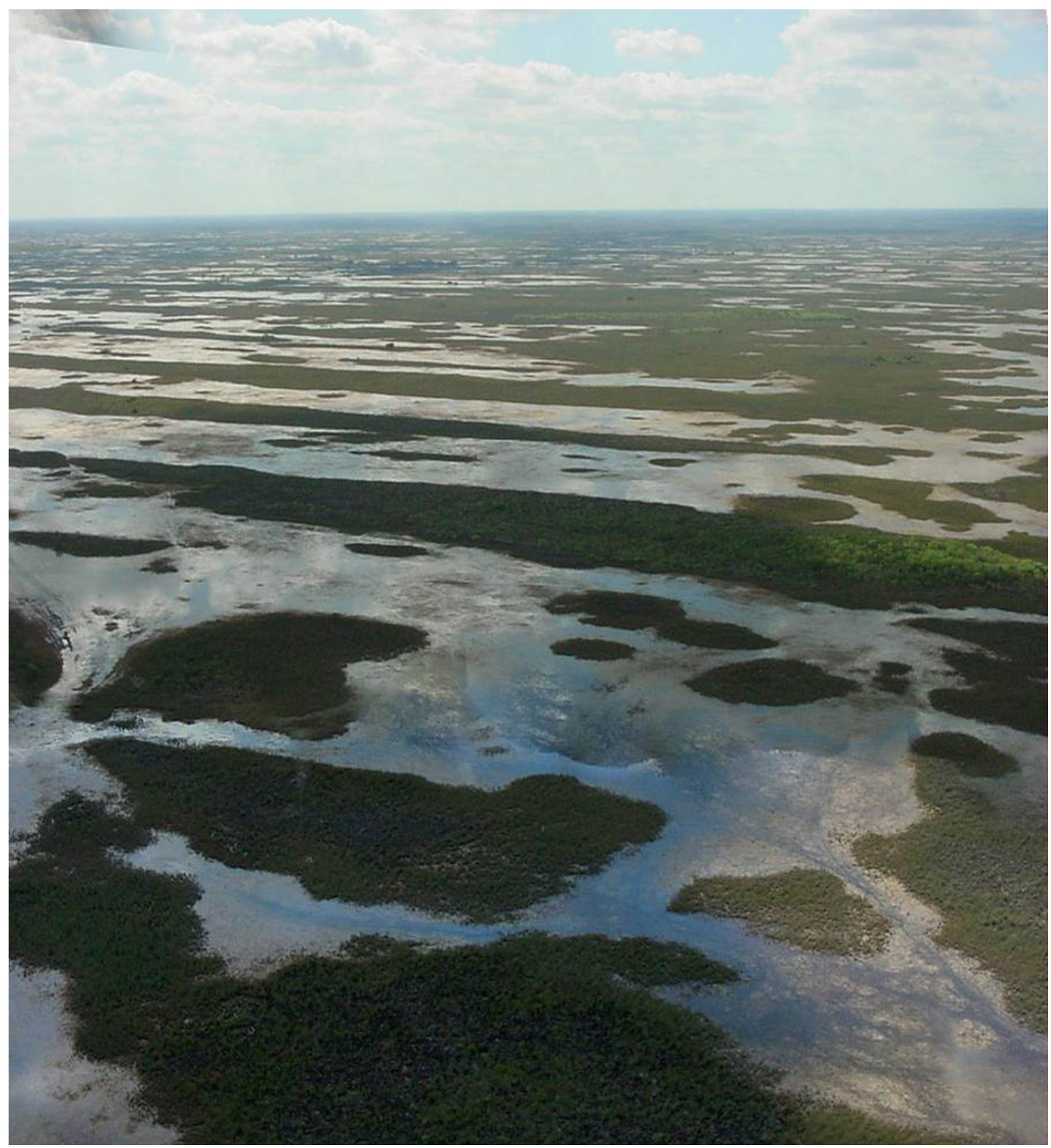

Figure 1. Ridge and Slough landscape of the Everglades. Both ridges and sloughs run roughly parallel to water flow roughly in the north/south direction. (Image courtesy of Robert Sobczak, National Park Service). 


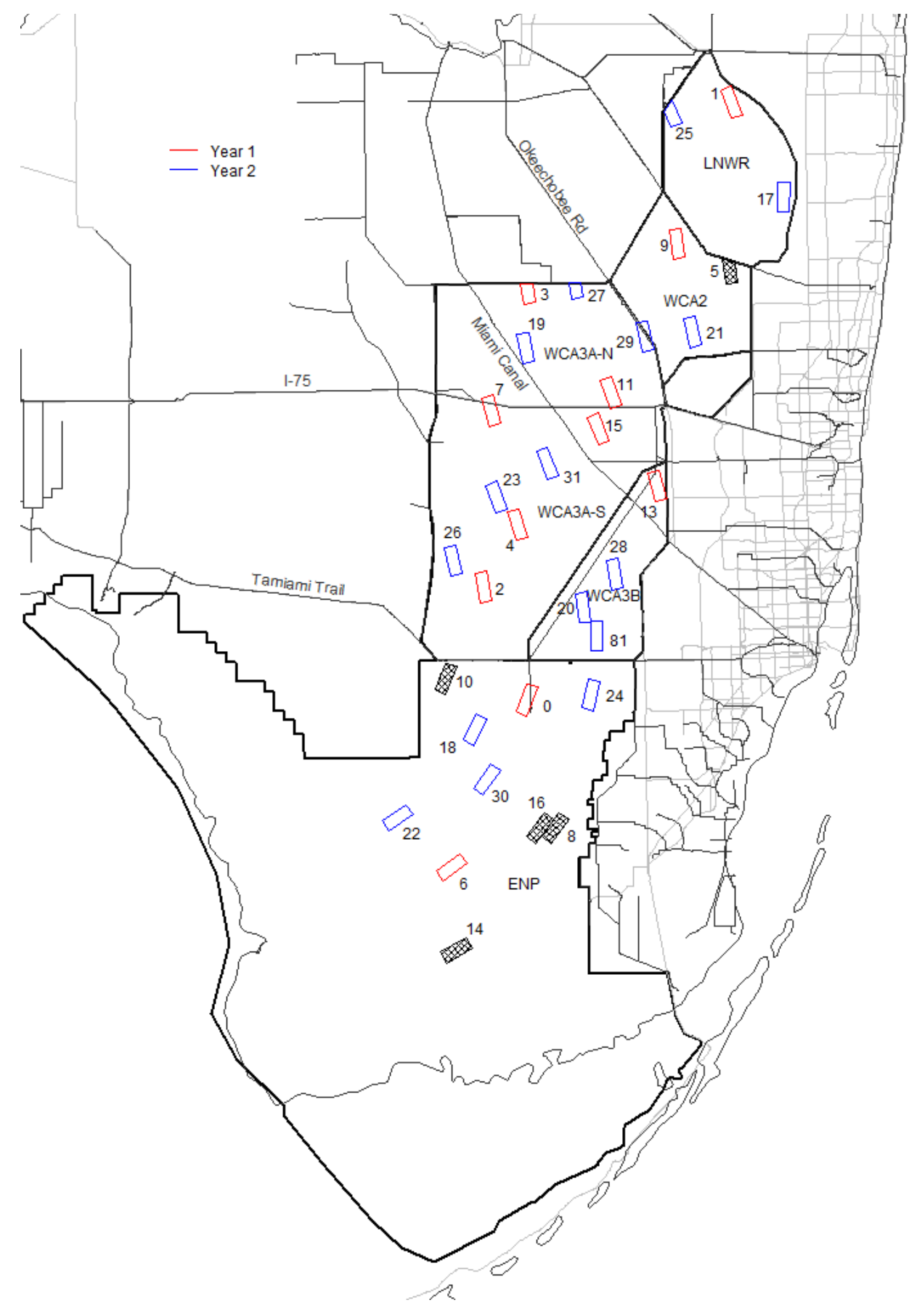

Figure 2. Site map with 27 landscape blocks (PSUs) from two years of sampling. Red PSUs (PSU 0 to PSU 15) are from year one (2010); blue (PSU 17 to PSU 81) are from year two (2011). The PSUs are $2 \mathrm{~km}$ by $5 \mathrm{~km}$ and oriented parallel to flow and contain up to 240 sampling points in a spatially-stratified design. Check-marked PSUs in ENP were sampled but outside the historic Ridge and Slough landscape and not analyzed. Dense stands of cattail prohibited sampling of PSU 5 in WCA 2. 

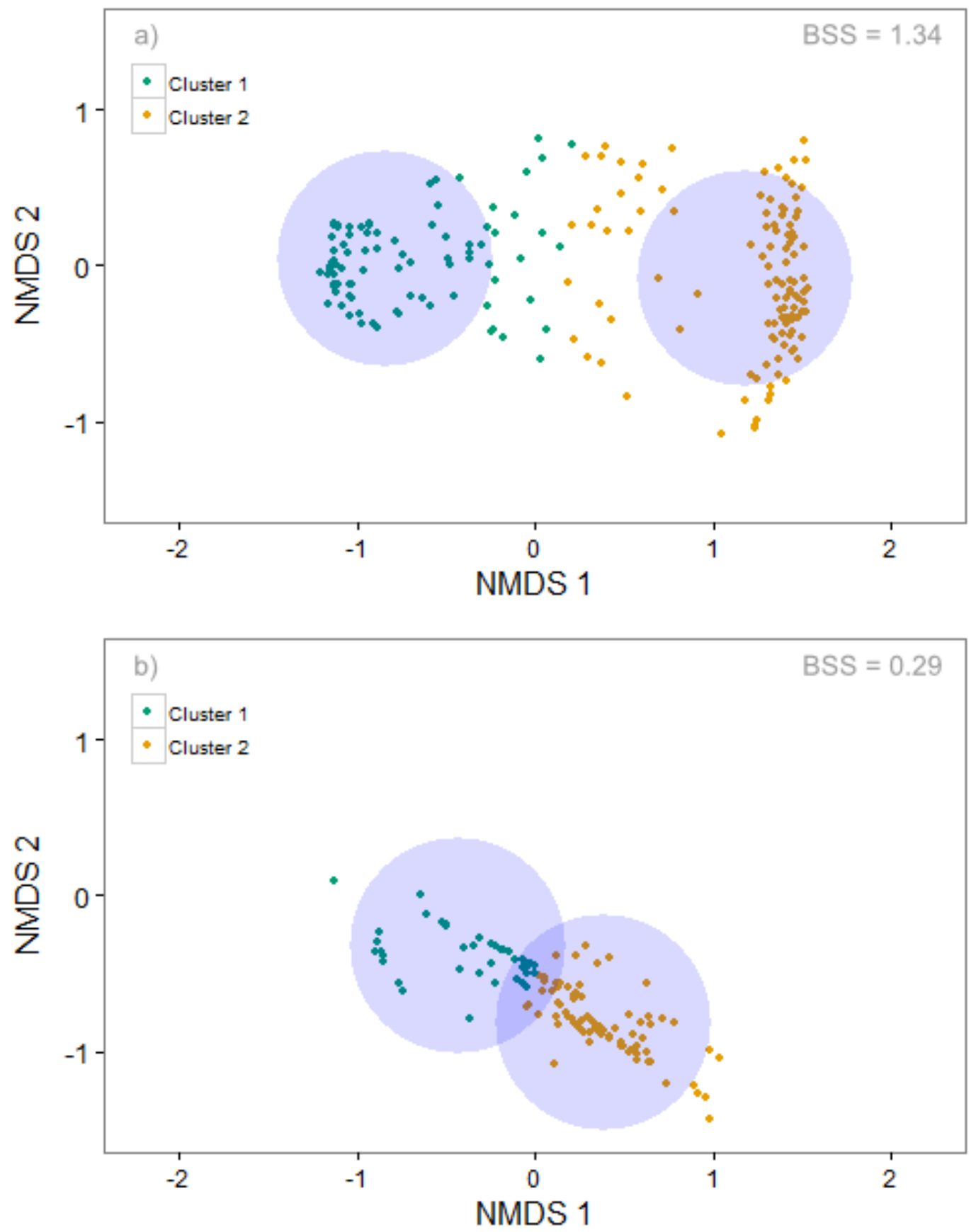

Figure 3. Two PSUs ordinated by NMDS and clustered by k-means. Sampling points are positioned on the NMDS based on dissimilarities in each sampling points' species composition. Clustering separates sampling points within PSUs using a nearest neighbor approach. In (a), PSU 23 clusters are relatively far apart, indicating a significant segregation of sampling points, or a relatively conserved PSU. In (b), PSU 9 clusters are closer, indicating a loss of vegetation community distinctness, or a relatively degraded PSU. 


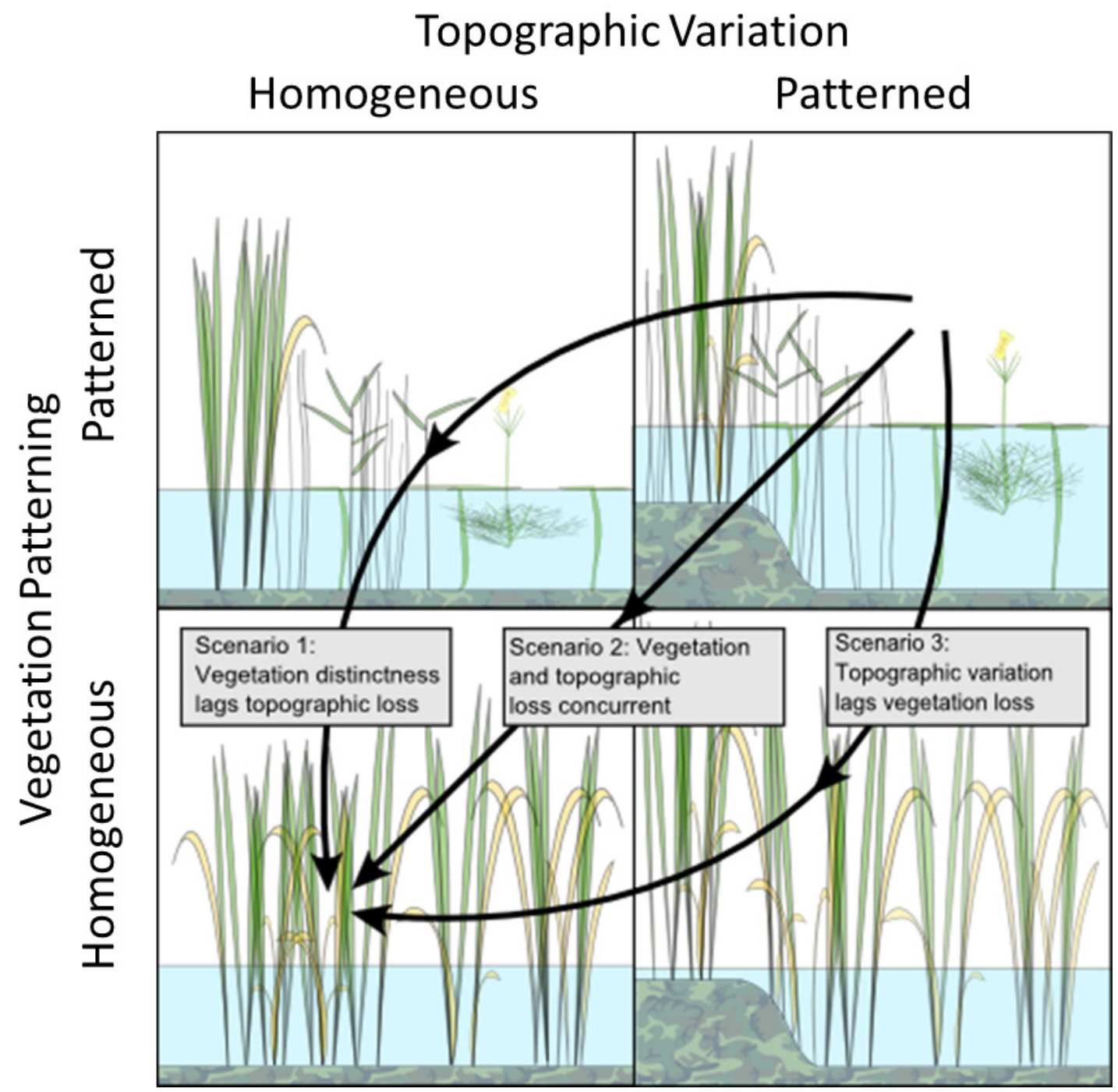

Figure 4. Schematic of lag scenarios following a reduction in the hydrologic regime: (1) topographic variation is reduced after modification of the hydrologic regime, followed by a lagged response in vegetation community distinctness changes; (2) vegetation community distinctness declines after modification of the hydrologic regime, followed by a lagged response in topographic variation; (3) vegetation community distinctness amd topographic variation loss is simultaneously reduced, with both processes lagging behind modification of the hydrologic regime. 

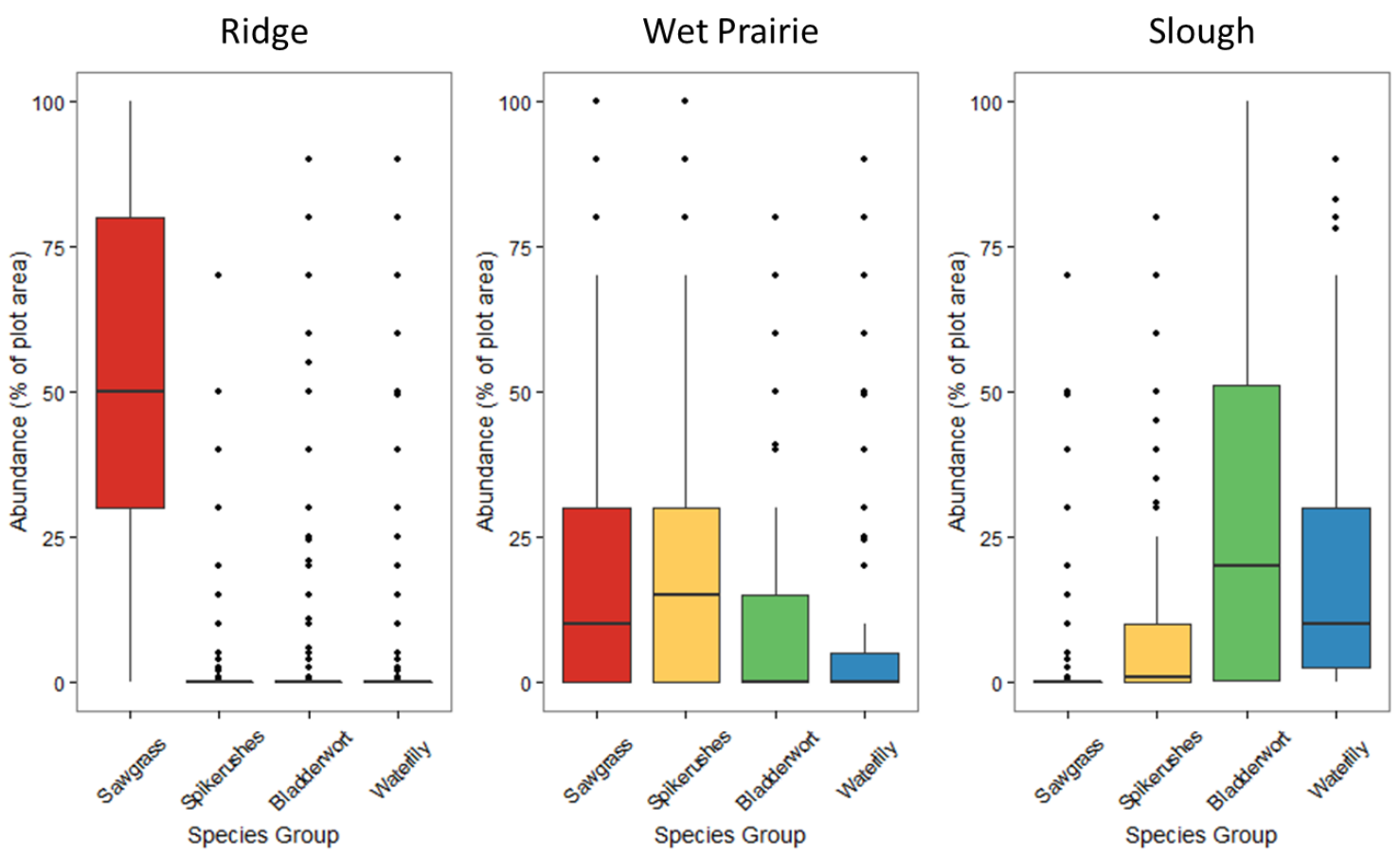

Figure 5. Major species' abundances within the most common field designated communities. Sawgrass is Cladium jamaicense; Spikerushes are Eleocharis celulosa, Elecocharis Eleongata, Eleocharis interstincta, and an unidentified Eleocharis species; Bladderworts are Utricularia cornuta, Utricularia foliosa, Utricularia gibba, Utricularia purpurea, and an unidentified Utricularia species; Waterlily is Nymphaea odorata. 

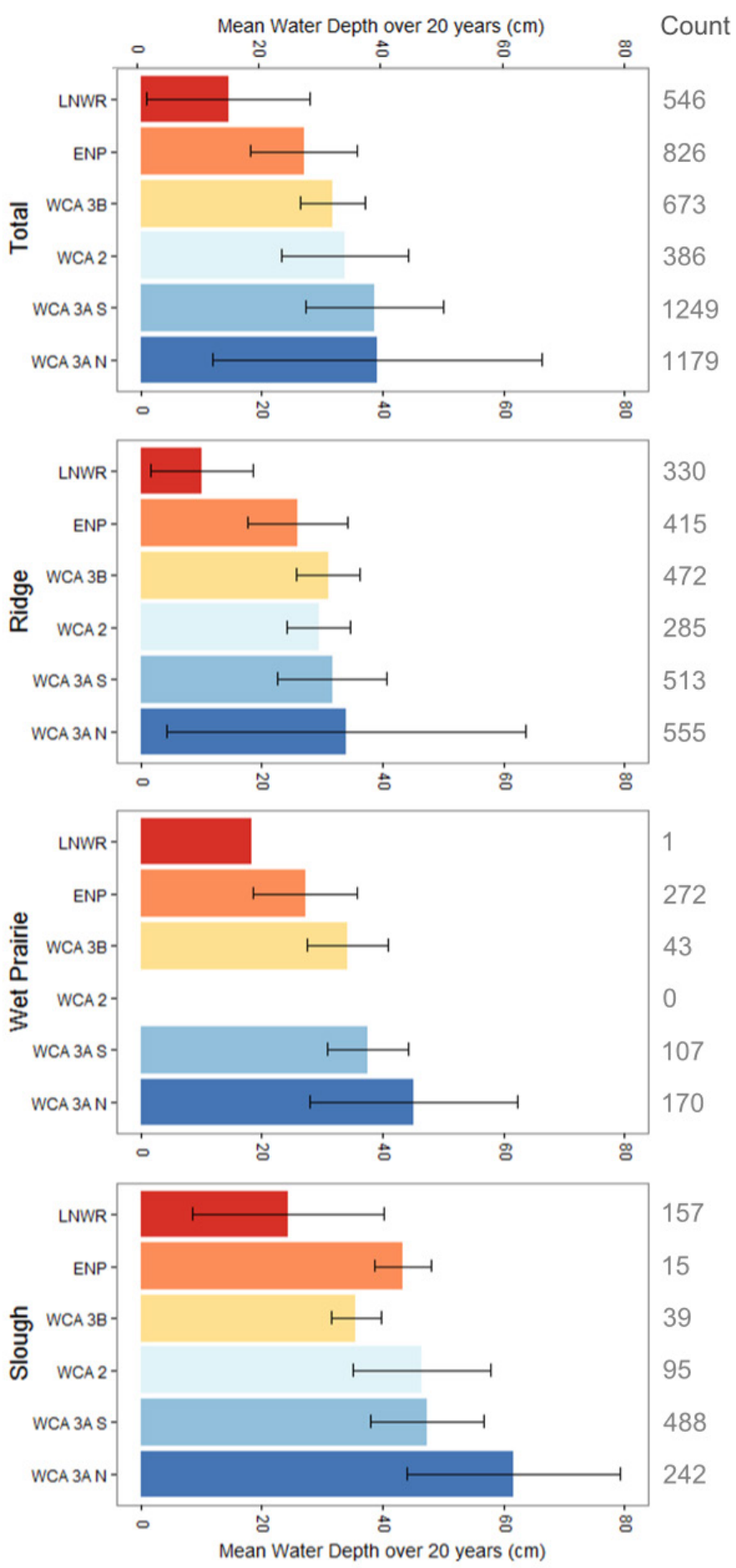

Figure 6. Hydrologic regimes for major communities among basins. ENP is Everglades National Park; LNWR is Loxahatchee National Wildlife Refuge; WCA 2; Water Conservation Area 2; WCA 3A S is Water Conservation Area 3A South; WCA 3A N is Water Conservation Area 3A North; WCA 3B is Water Conservation Area 3B. Error bars is the standard deviation associated with water depth within basins. Counts are the total counts of communitiy types within each basin. No wet prairies were found in WCA 2. 


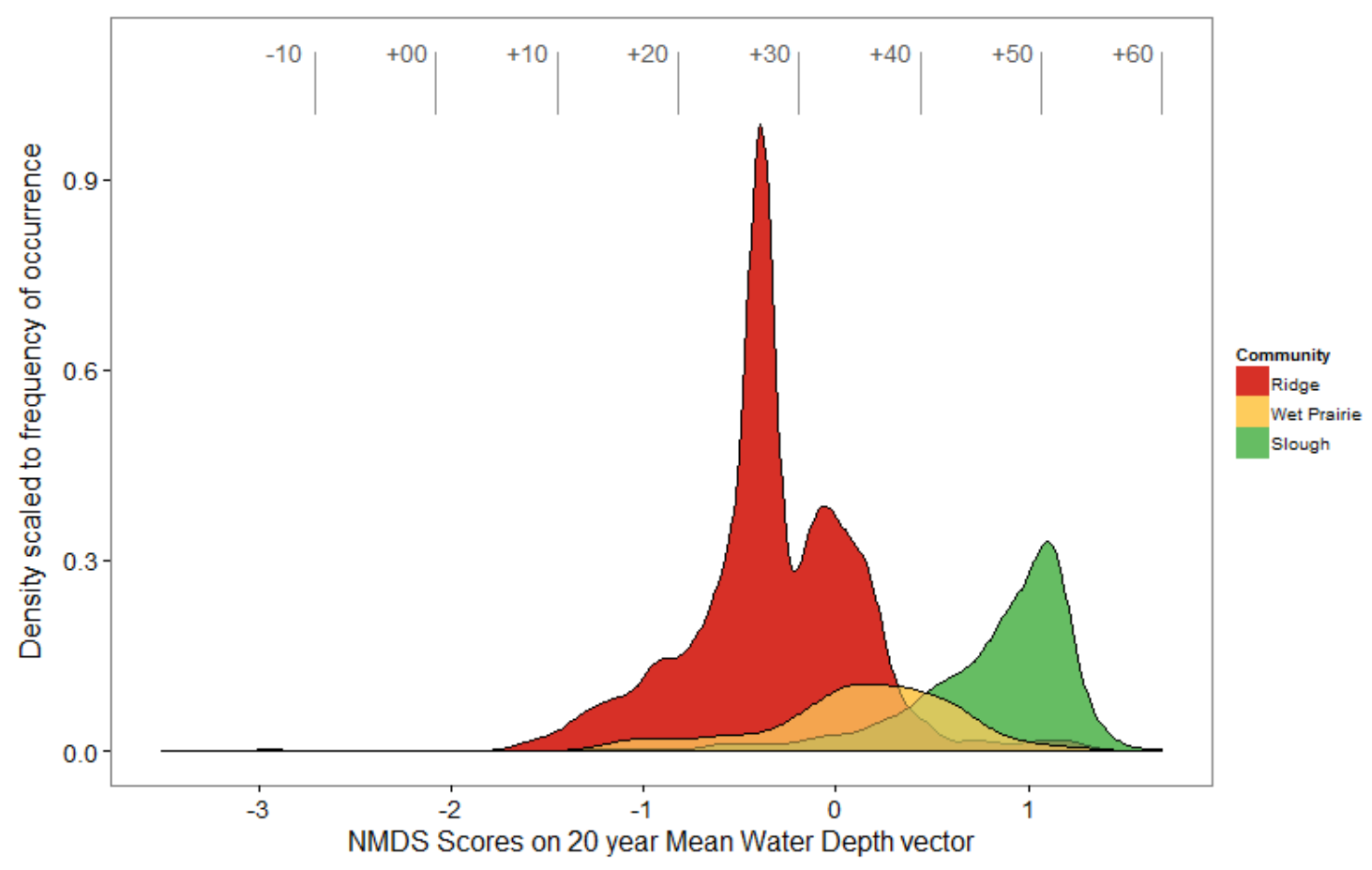

Figure 7. NMDS ordination scores for the three most abundant vegetation communities. The NMDS is rotated to the hydrologic (mean water depth over 20 years) axis. The ridge, wet prairie and slough communities comprise $86.4 \%$ of all sampling points. The ruler at the top is the average water depth over 20 years across the hydrologic vector on the NMDS ordination space. 

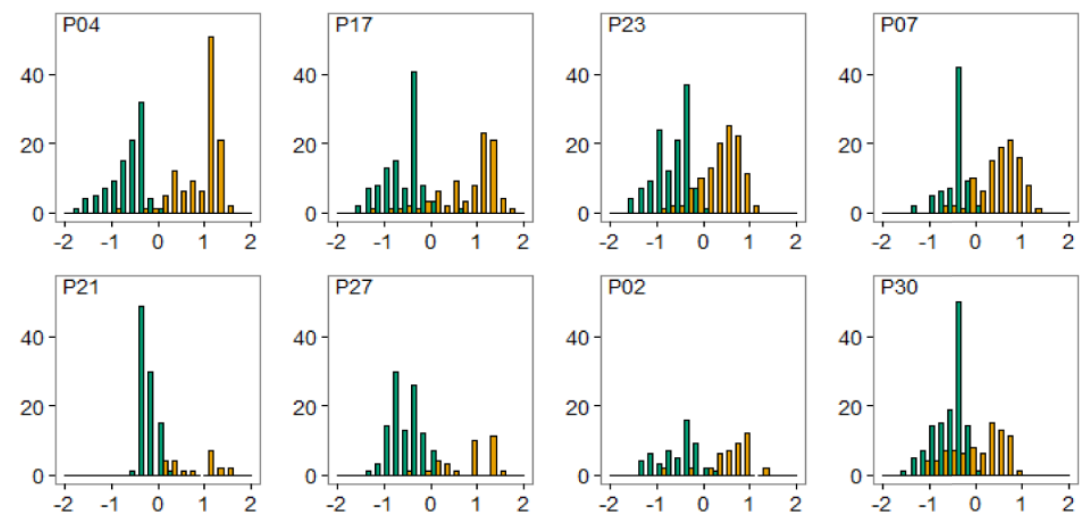

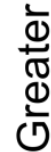
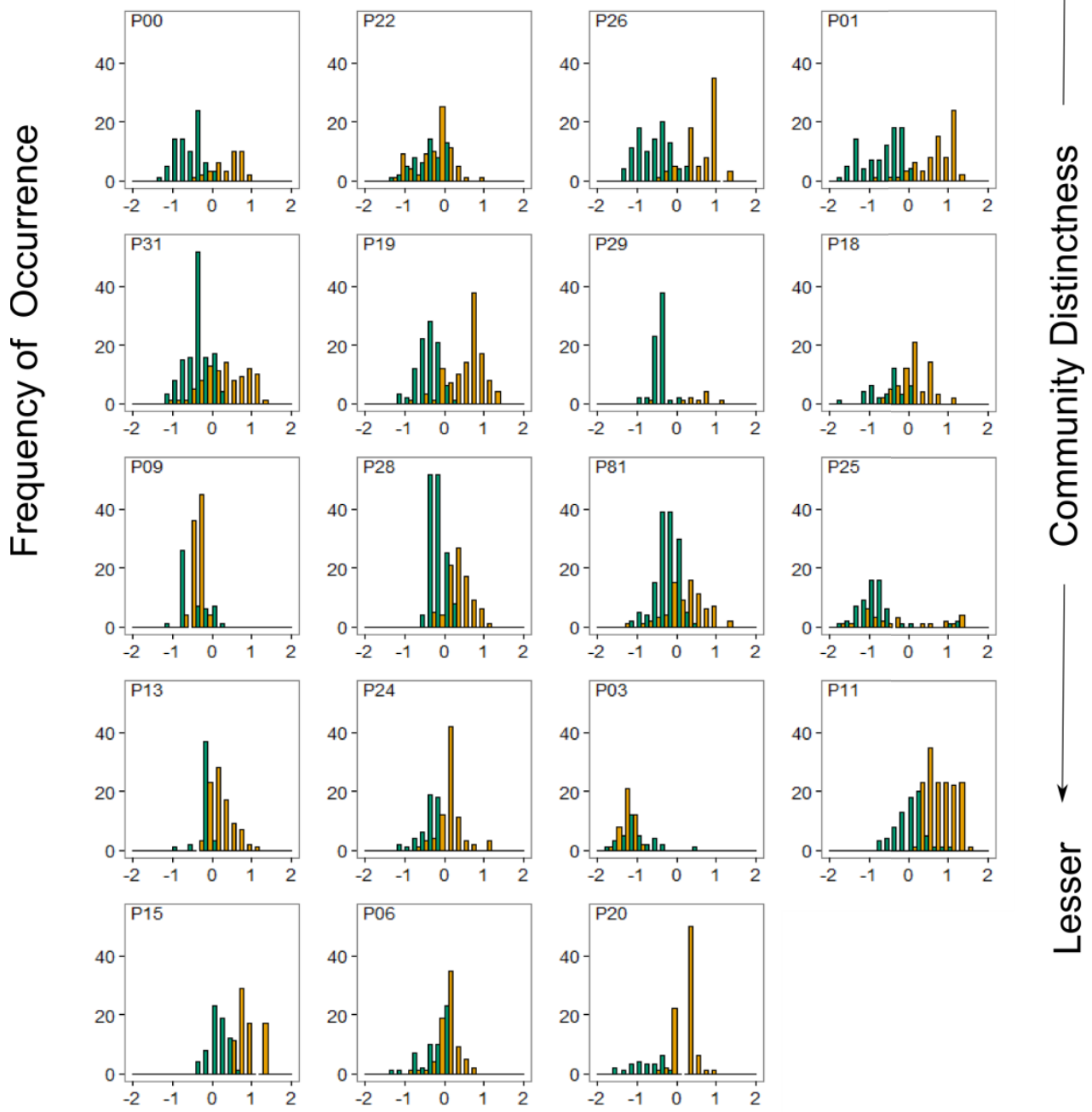

\section{NMDS Score Along Hydrologic Axis}

Figure 8. NMDS ordination site scores within PSUs rotated to the hydrologic axis. The NMDS is rotated to the hydrologic (mean water depth over 20 years) axis. From left to right and top to bottom, PSUs are sorted by distinctness (k-means derived cluster distance). Red and blue bars correspond to within-PSU k-means derived clusters. 


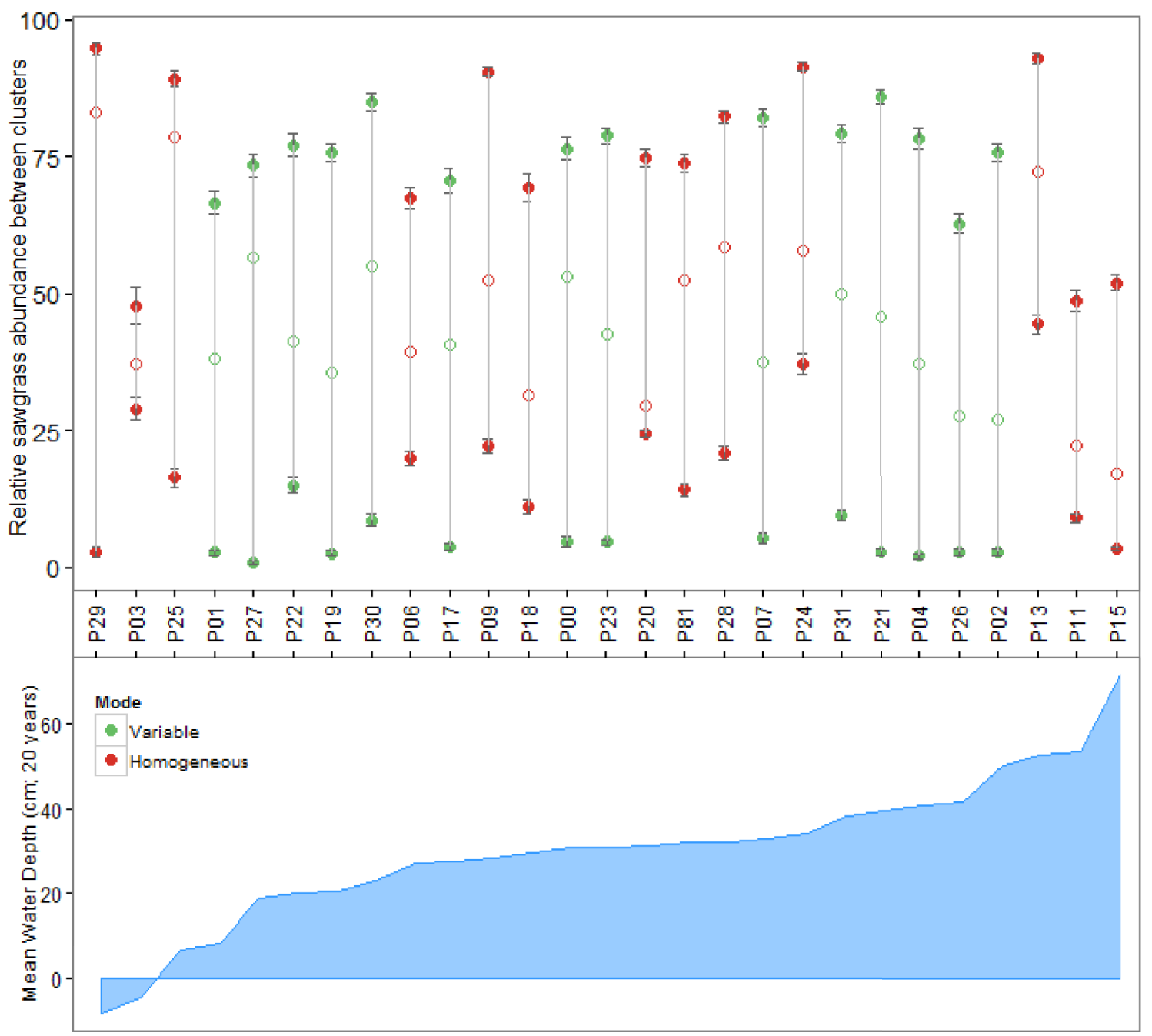

Figure 9. Sawgrass relative abundance for each cluster within each PSU. Sawgrass (Cladium jamaicense) closed circles are calculated from the mean abundances within each PSU's k-means cluster analysis. The open circles are the mean relative abundances within each PSU. Green (lighter) are relatively distinct PSUs (as designated by the kernel density troughs in Figure 14a). Red (darker) are relatively vegetatively degraded PSUs. Error bars are standard errors. The PSUs are ranked by mean 20 year water depth. 

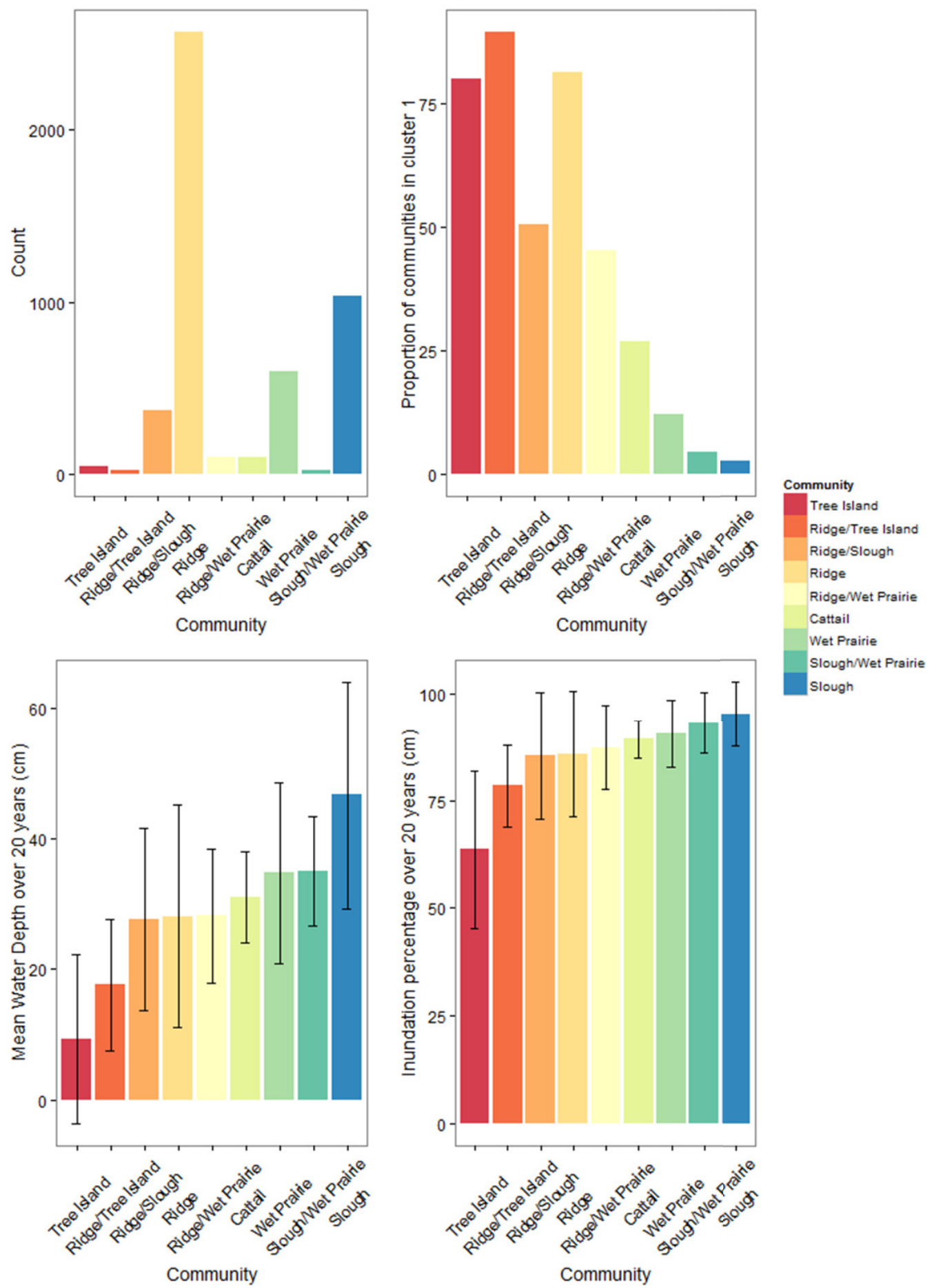

Figure 10. Community statistics: count, cluster segregation, and hydrologic regimes. Count is the total number of each community across all 27 PSUs within the Ridge and Slough landscape. The proportion of communities in cluster 1 is derived from the global $\mathrm{k}$-means cluster analysis. Mean water depth over 20 years and inundation frequency (hydroperiod) are shown for each community. Error bars are standard deviations. The PSUs are ranked by 20 year mean water depth. 


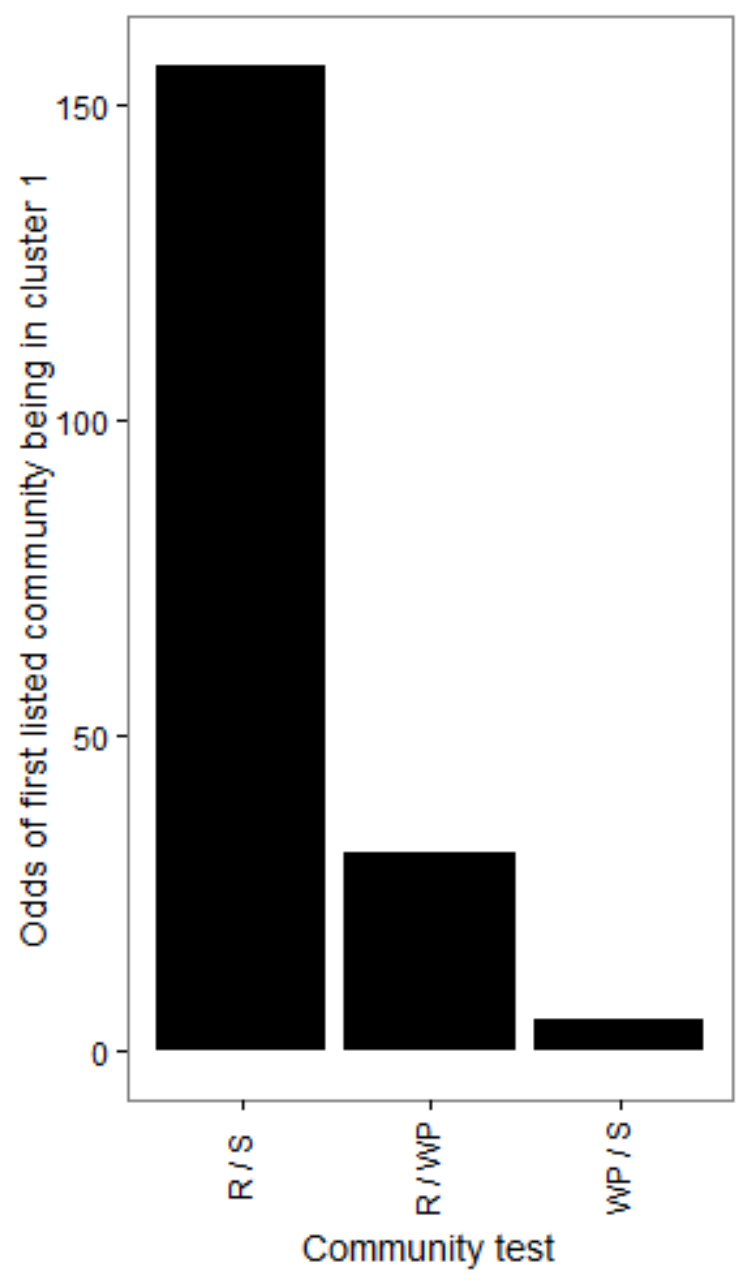

Figure 11. Odds Ratio Test for k-means derived clusters within communities. $R$ is the ridge community; WP is wet prairie; $\mathrm{S}$ is slough. Communities across the Ridge and Slough landscape were designated in the field and the k-means clustering was conducted globally (across all PSUs simultaneously). The test examines the odds of the first community being in cluster 1 compared to the second community (for example, the first bar shows that ridges are 156.3 times more likely to be in cluster 1 compared to sloughs). 


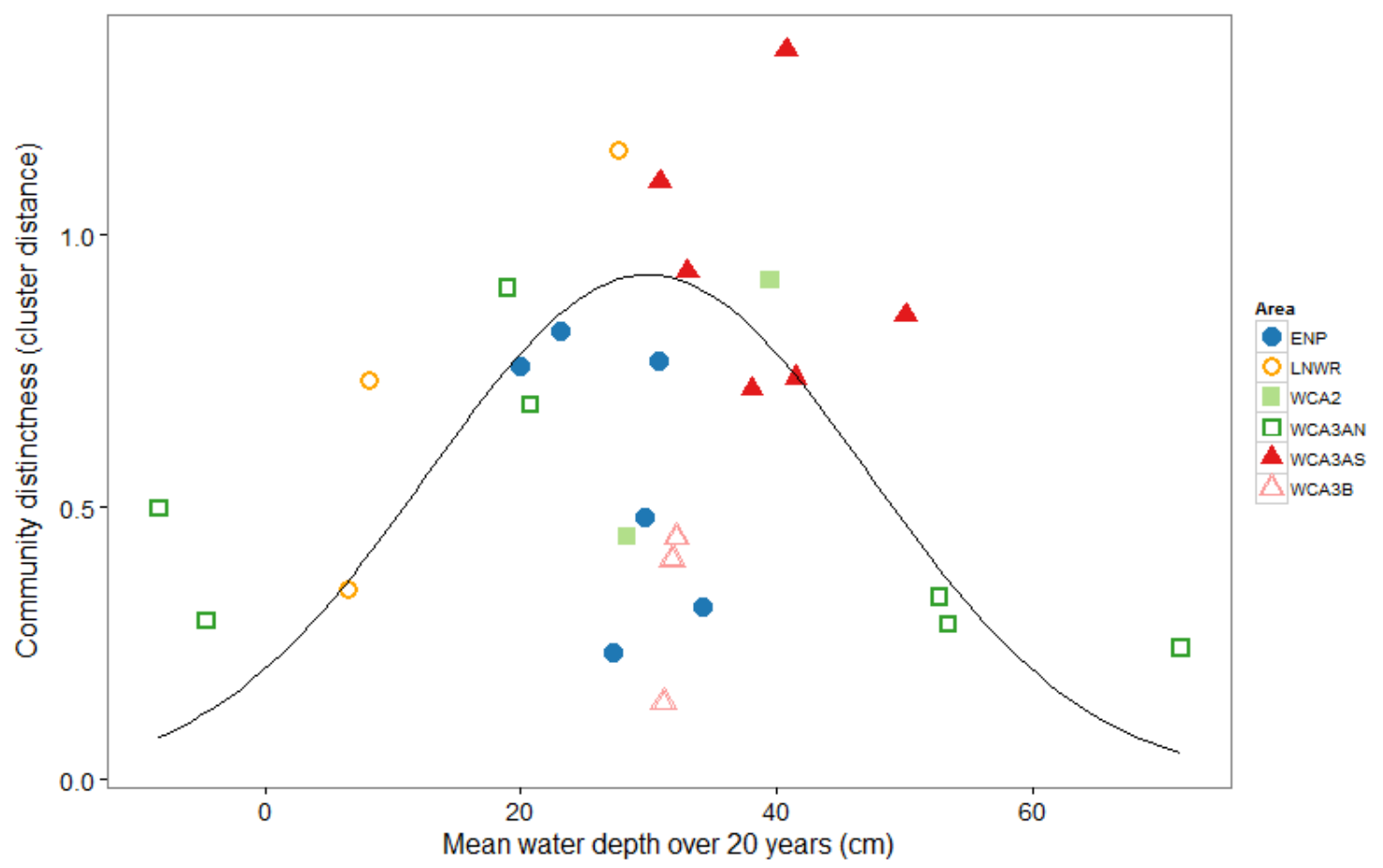

Figure 12. Vegetation community distinctness along the hydrologic gradient. Distinctness was measured by the distance between k-means derived clusters within each PSU from the NMDS ordination space. The distribution was fitted using a Gaussian function for each sampling point averaged over 20 years of variable water depth. The distribution's mean is the mean of the PSUs 20 year water depths; the standard deviation of the distribution is the standard deviation of the PSUs 20 year water depths. ENP is Everglades National Park; LNWR is Loxahatchee National Wildlife Refuge; WCA 2; Water Conservation Area 2; WCA 3A S is Water Conservation Area 3A South; WCA 3A $\mathrm{N}$ is Water Conservation Area 3A North; WCA 3B is Water Conservation Area 3B. 


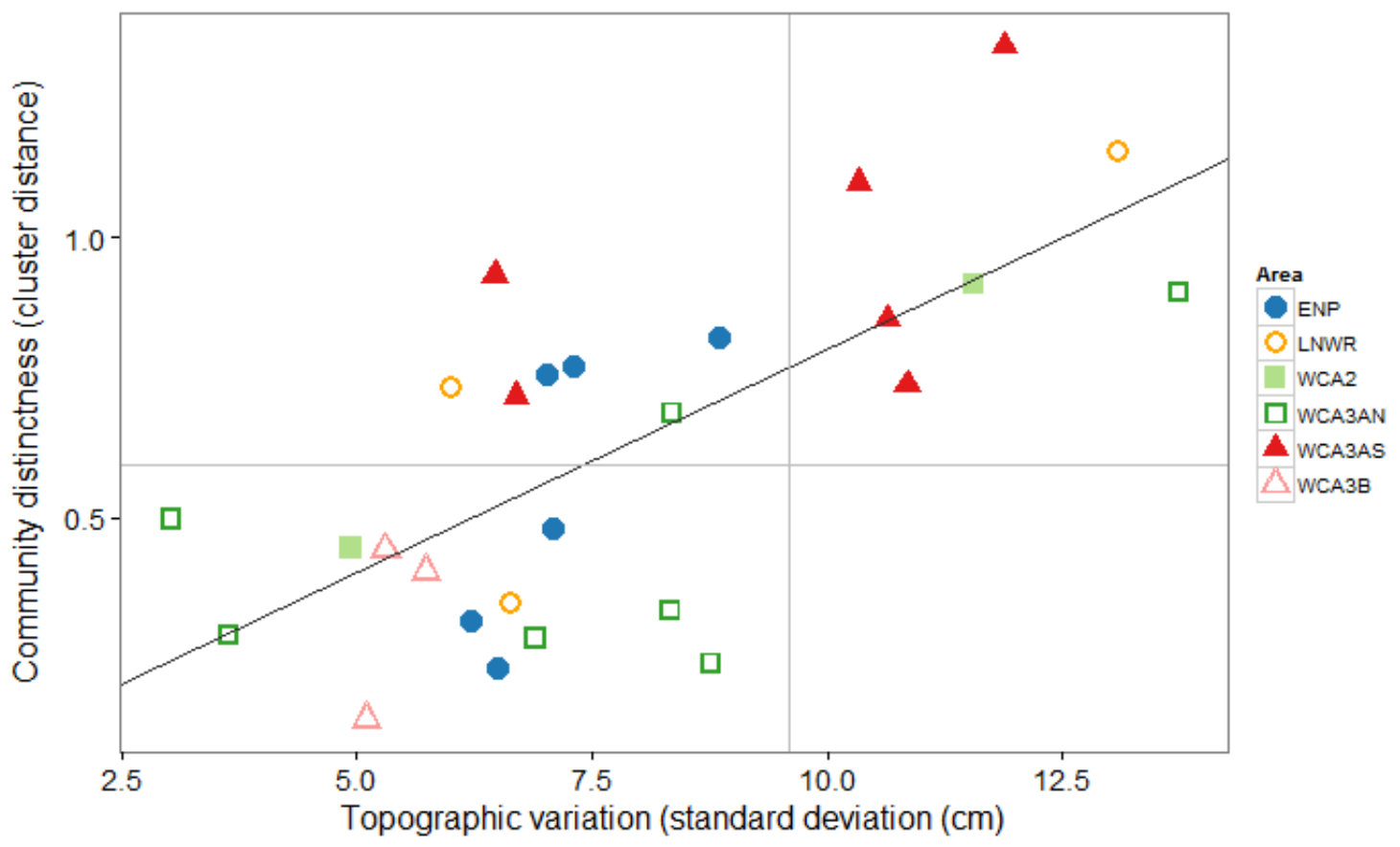

Figure 13. Vegetation community distinctness' association with topographic variation. $\left(r^{2}\right.$ $=0.49, \operatorname{Pr}(>F)<0.001$.) Distinctness was measured by the distance between k-means derived clusters within each PSU from the NMDS ordination space. ENP is Everglades National Park; LNWR is Loxahatchee National Wildlife Refuge; WCA 2; Water Conservation Area 2; WCA 3A S is Water Conservation Area 3A South; WCA 3A N is Water Conservation Area 3A North; WCA 3B is Water Conservation Area 3B. 

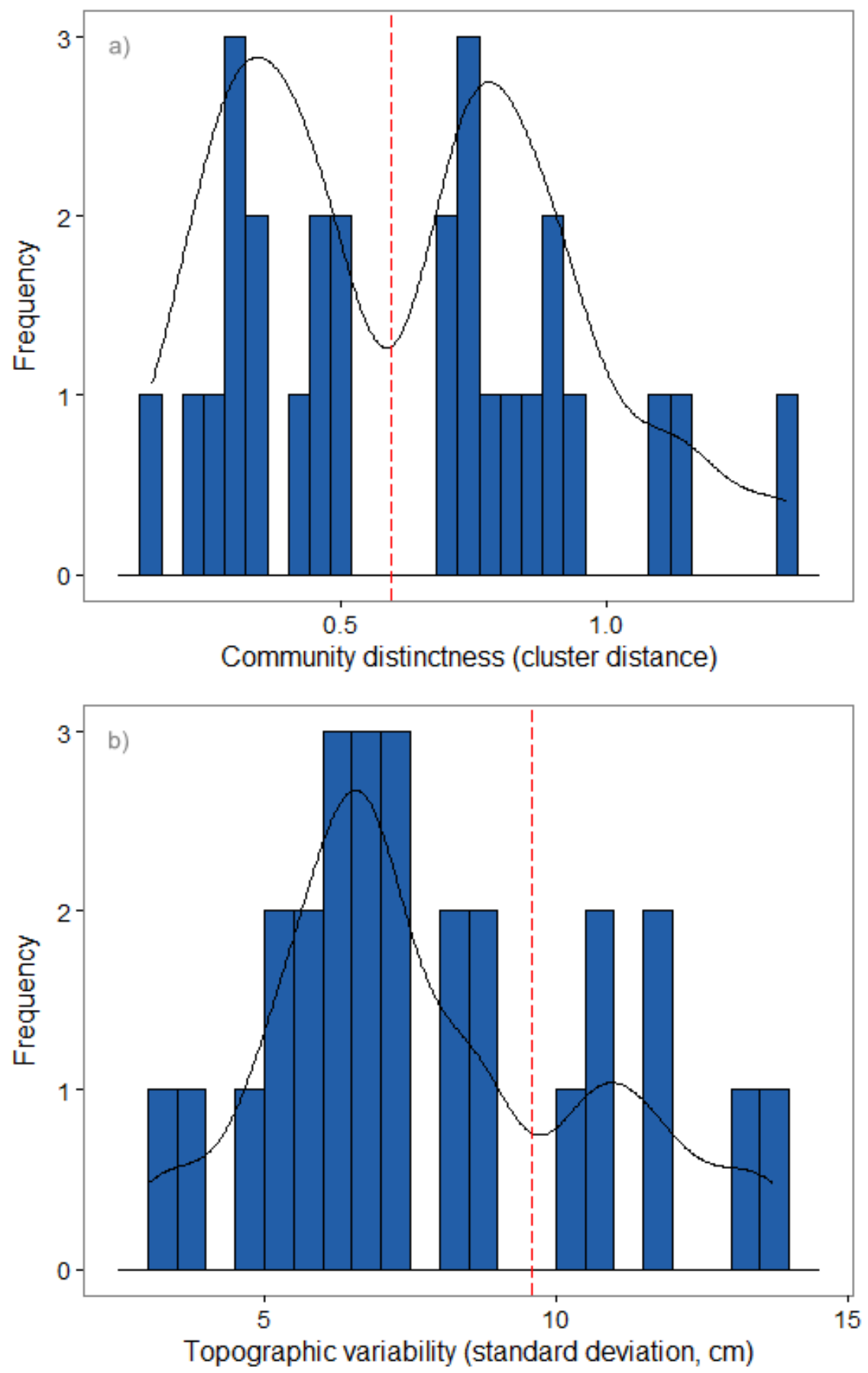

Figure 14. Vegetation community distinctness and topographic variation counts and $\mathrm{KDE}$. Vegetation community distinctness is derived from the k-means derived between cluster distance for each PSU across the Ridge and Slough landscape (6a); topographic variability is derived from each PSU's mean water depth standard deviation (6b). The KDE (kernel density estimations) troughs are used to separate each process into conserved and degraded condition. 


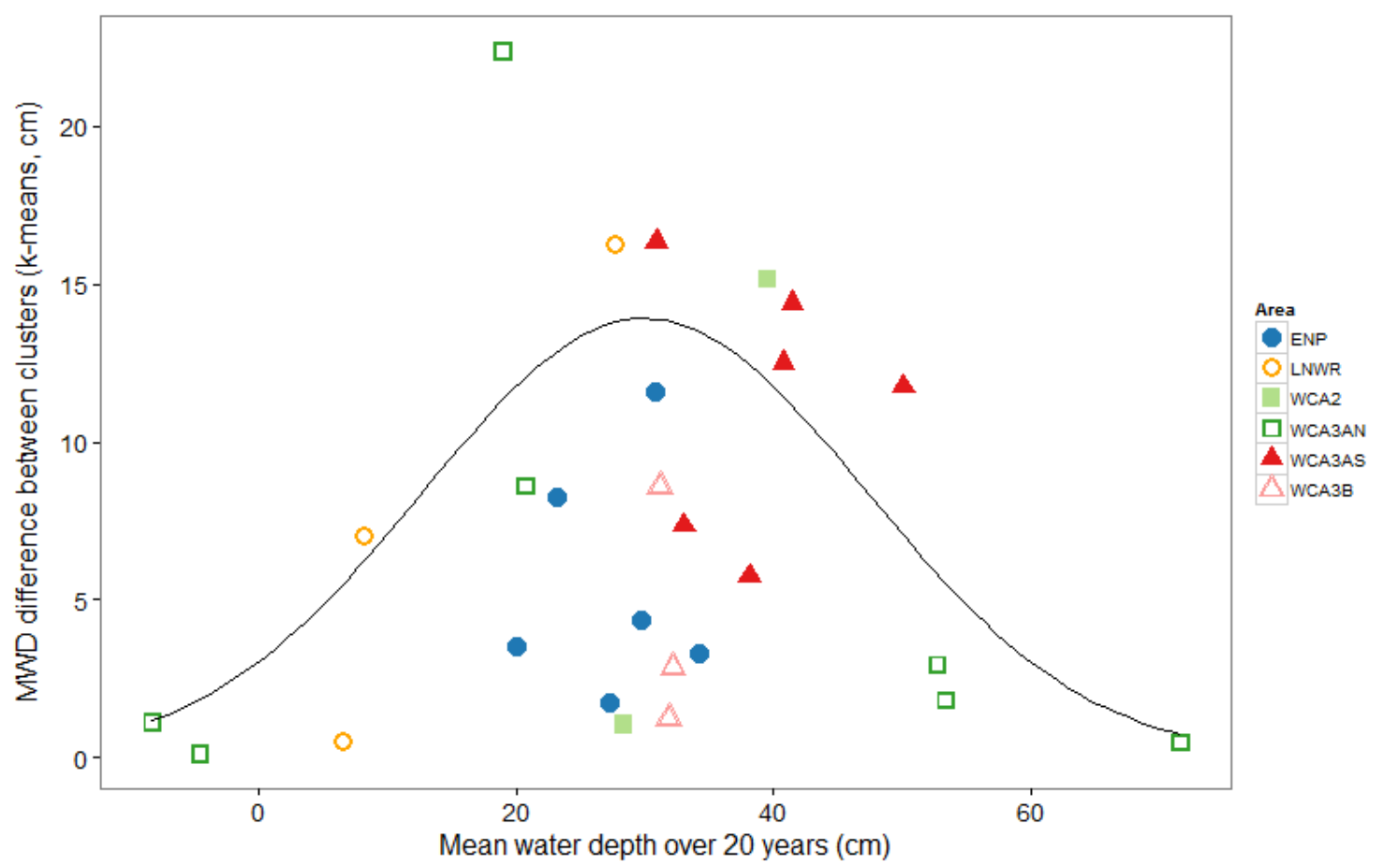

Figure 15. The k-means cluster distance difference in MWD across the hydrologic gradient. The mean water depth difference (MWD; $\mathrm{cm}$ ) between the two k-means derived clusters across the Ridge and Slough landscape are compared to the hydrologic gradient defined as the mean water depth for each PSU over the 20 year hydrologic record. The distribution was fitted using a Gaussian function for each sampling point averaged over 20 years of variable water depth. The distribution's mean is the mean of the PSUs 20 year water depths; the standard deviation of the distribution is the standard deviation of the PSUs 20 year water depths. ENP is Everglades National Park; LNWR is Loxahatchee National Wildlife Refuge; WCA 2; Water Conservation Area 2; WCA 3A S is Water Conservation Area 3A South; WCA 3A N is Water Conservation Area 3A North; WCA $3 B$ is Water Conservation Area 3B. 


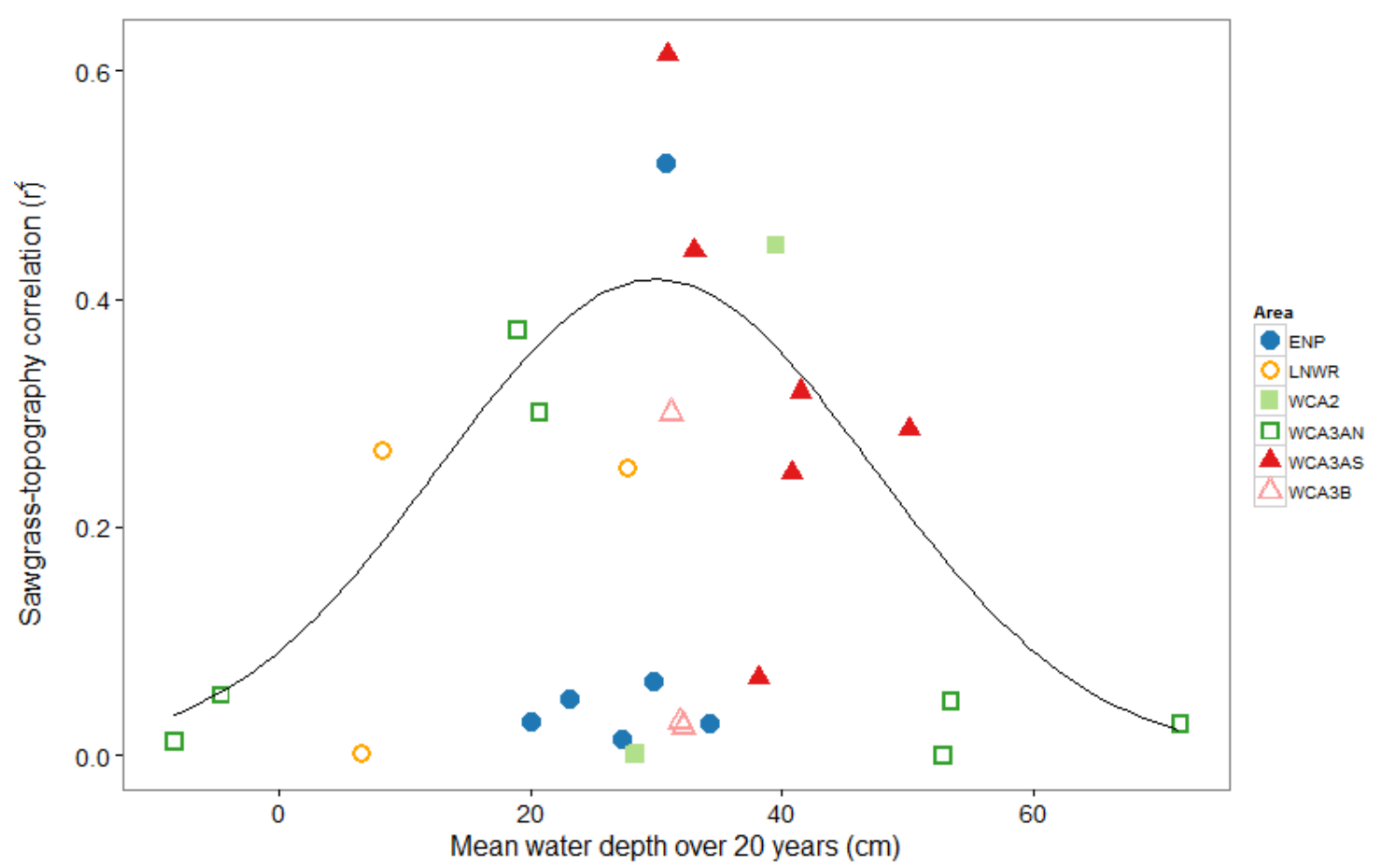

Figure 16. Sawgrass abundance and MWD correlation across the hydrologic gradient. Sawgrass (Cladium jamaicense) mean abundances within each PSU across the Ridge and Slough landscape is compared to the hydrologic gradient defined as the mean water depth $(\mathrm{cm})$ for a PSU over the 20 year time period. The distribution was fitted using a Gaussian function for each sampling point averaged over 20 years of variable water depth. The distribution's mean is the mean of the PSUs 20 year water depths; the standard deviation of the distribution is the standard deviation of the PSUs 20 year water depths. ENP is Everglades National Park; LNWR is Loxahatchee National Wildlife Refuge; WCA 2; Water Conservation Area 2; WCA 3A S is Water Conservation Area 3A South; WCA 3A N is Water Conservation Area 3A North; WCA 3B is Water Conservation Area 3B. 


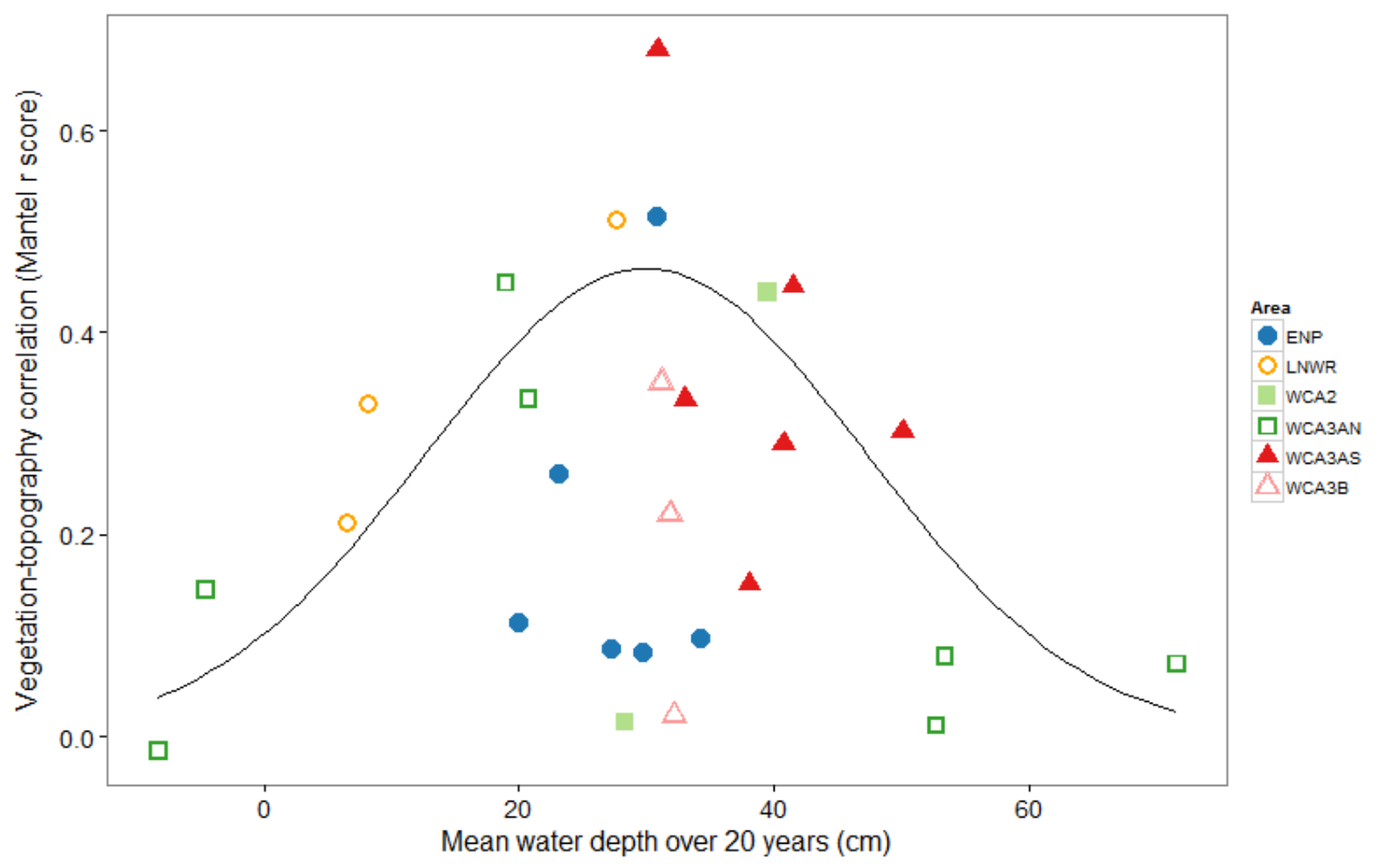

Figure 17. Mantel $r$ vegetation-topography correlation across the hydrologic gradient. The Mantel Test measures the correlation between vegetation abundances and topographic elevation (i.e., 20 year mean water depths) for each PSU across the Ridge and Slough landscape and is compared to the hydrologic gradient defined as the mean water depth $(\mathrm{cm})$ for a PSU over the 20 year time period. The distribution was fitted using a Gaussian function for each sampling point averaged over 20 years of variable water depth. The distribution's mean is the mean of the PSUs 20 year water depths; the standard deviation of the distribution is the standard deviation of the PSUs 20 year water depths. ENP is Everglades National Park; LNWR is Loxahatchee National Wildlife Refuge; WCA 2; Water Conservation Area 2; WCA 3A S is Water Conservation Area 3A South; WCA $3 A \mathrm{~N}$ is Water Conservation Area 3A North; WCA 3B is Water Conservation Area 3B. 


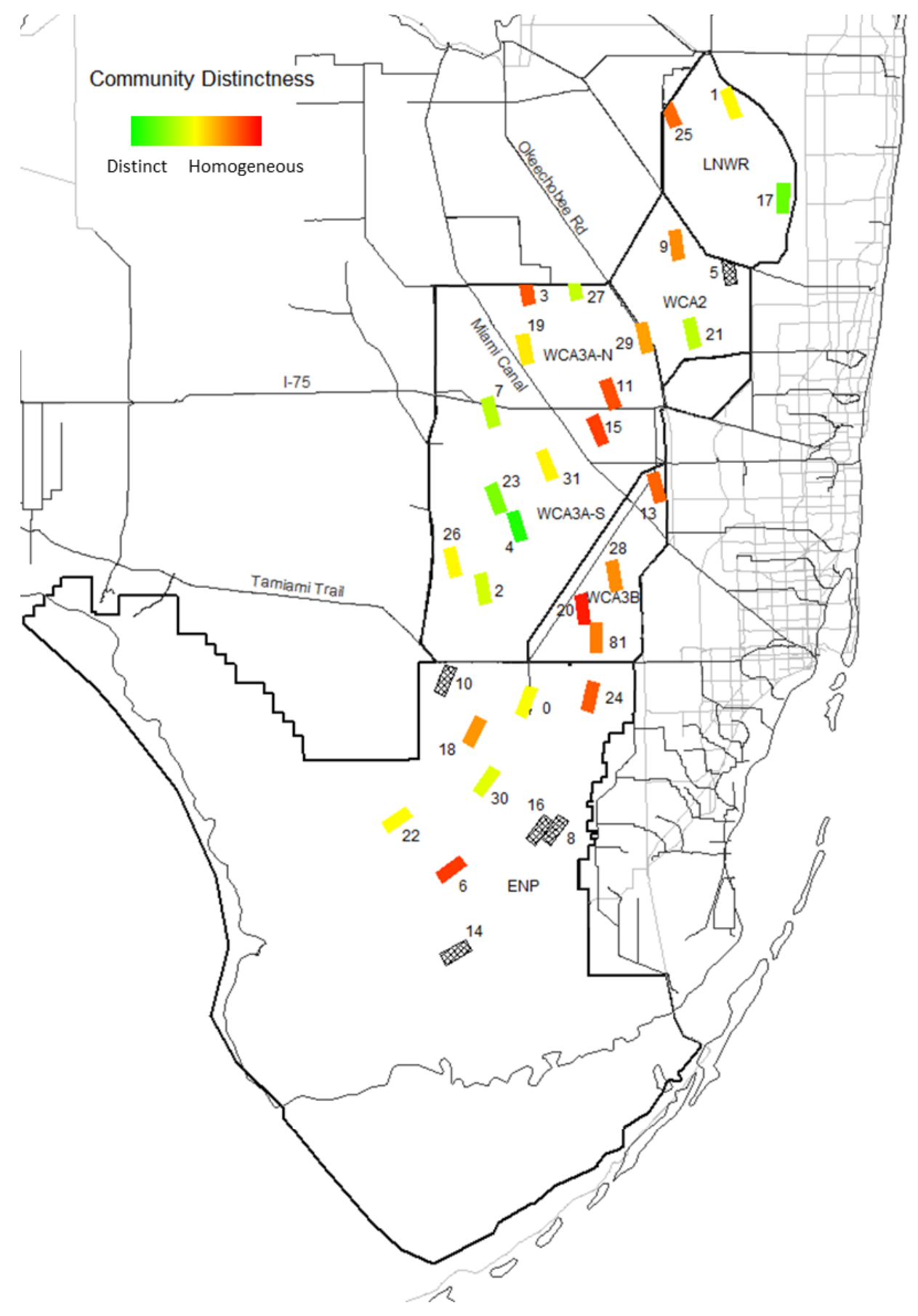

Figure 18. Vegetation community distinctness across the Ridge and Slough landscape. Green PSUs are most distinct and red the most homogeneous. Black hashed PSUs in the Everglades National Park are located outside the historic Ridge and Slough landscape. Dense stands of cattail prohibited sampling of PSU 5 in WCA 2. 


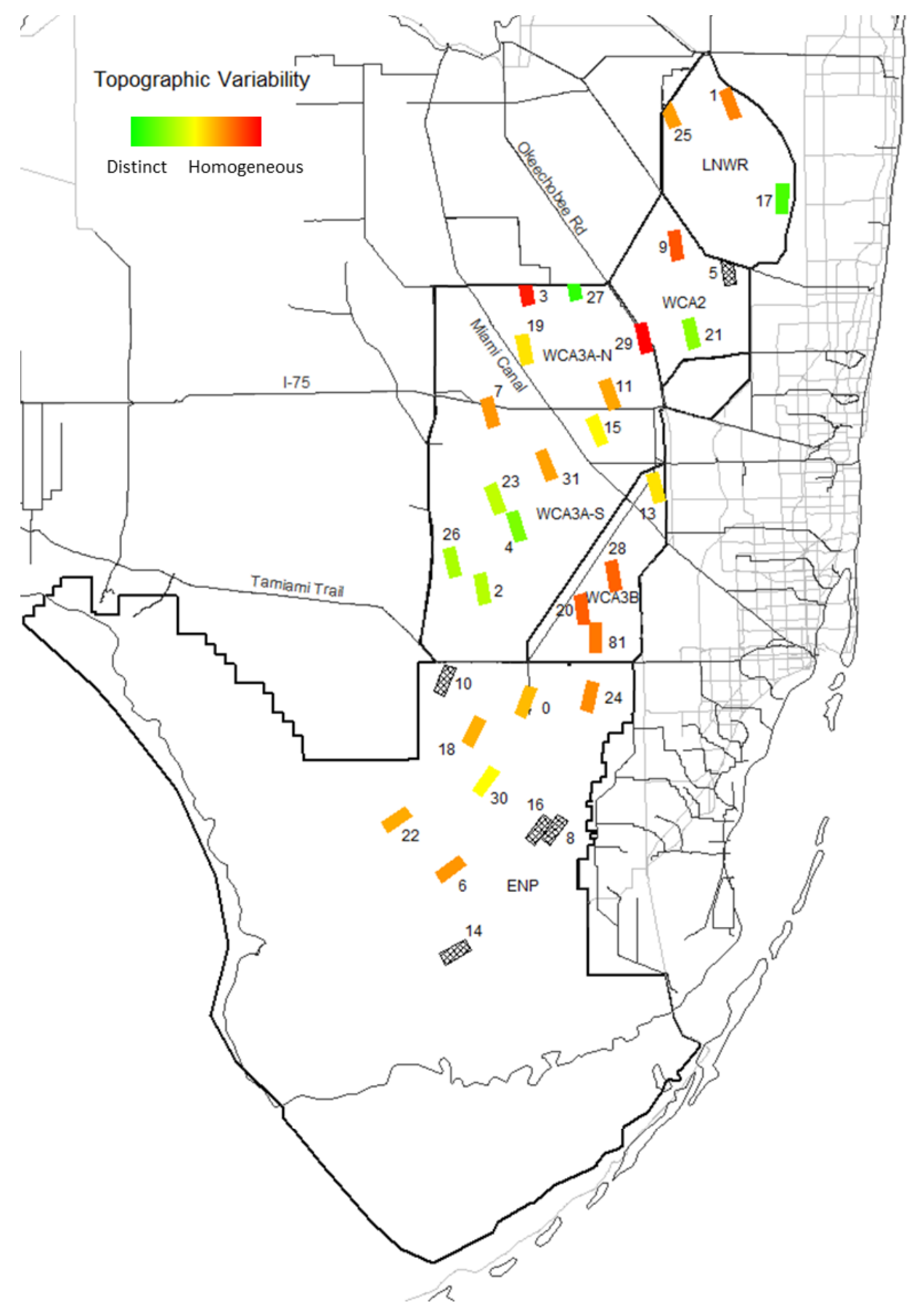

Figure 19. Topographic variation across the Ridge and Slough landscape. Green PSUs are most distinct and red the most homogeneous. Black hashed PSUs in the Everglades National Park are located outside the historic Ridge and Slough landscape. Dense stands of cattail prohibited sampling of PSU 5 in WCA 2. 


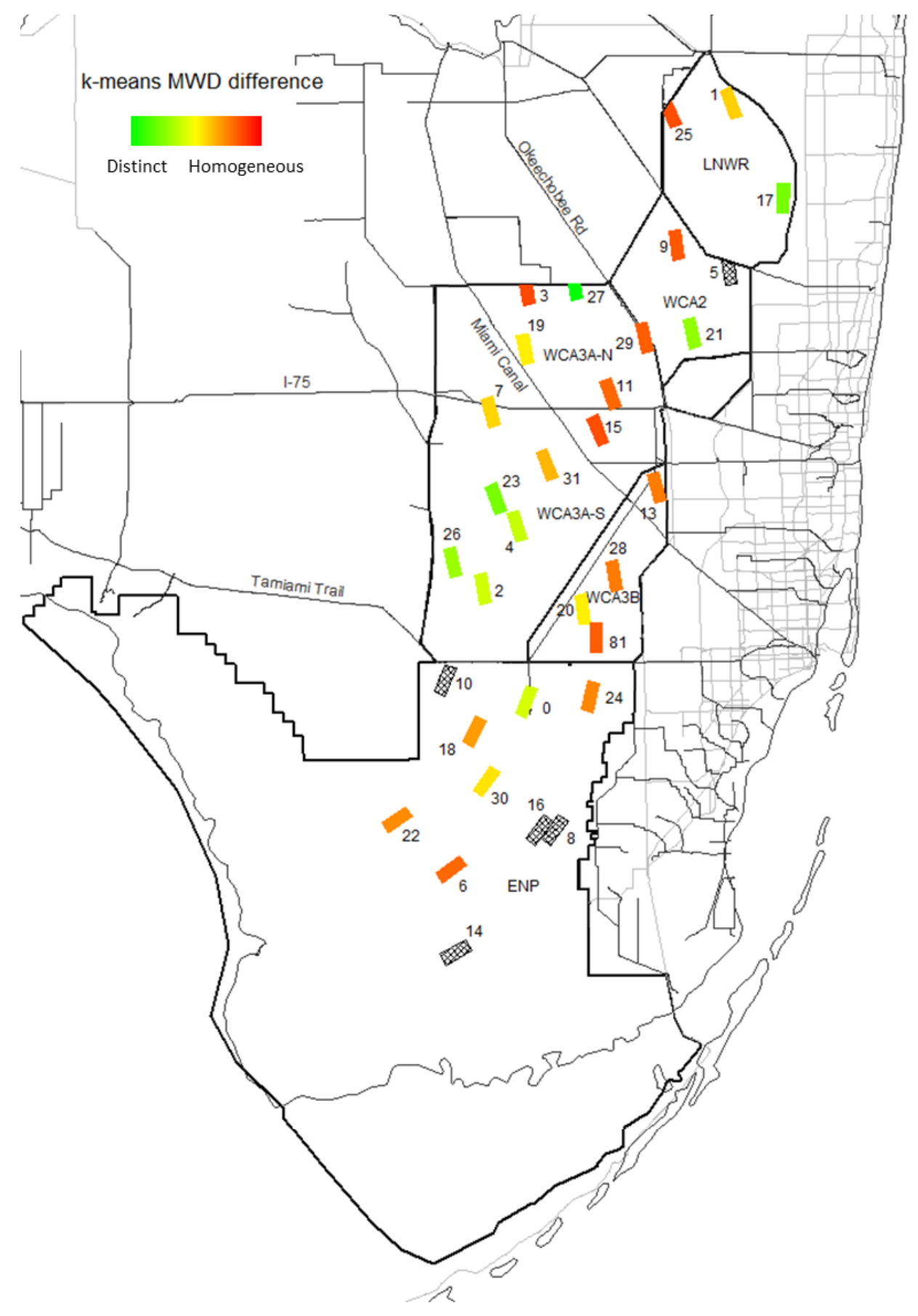

Figure 20. The k-means difference in MWD across the Ridge and Slough landscape. Green PSUs are most distinct and red the most homogeneous. Black hashed PSUs in the Everglades National Park are located outside the historic Ridge and Slough landscape. Dense stands of cattail prohibited sampling of PSU 5 in WCA 2. 


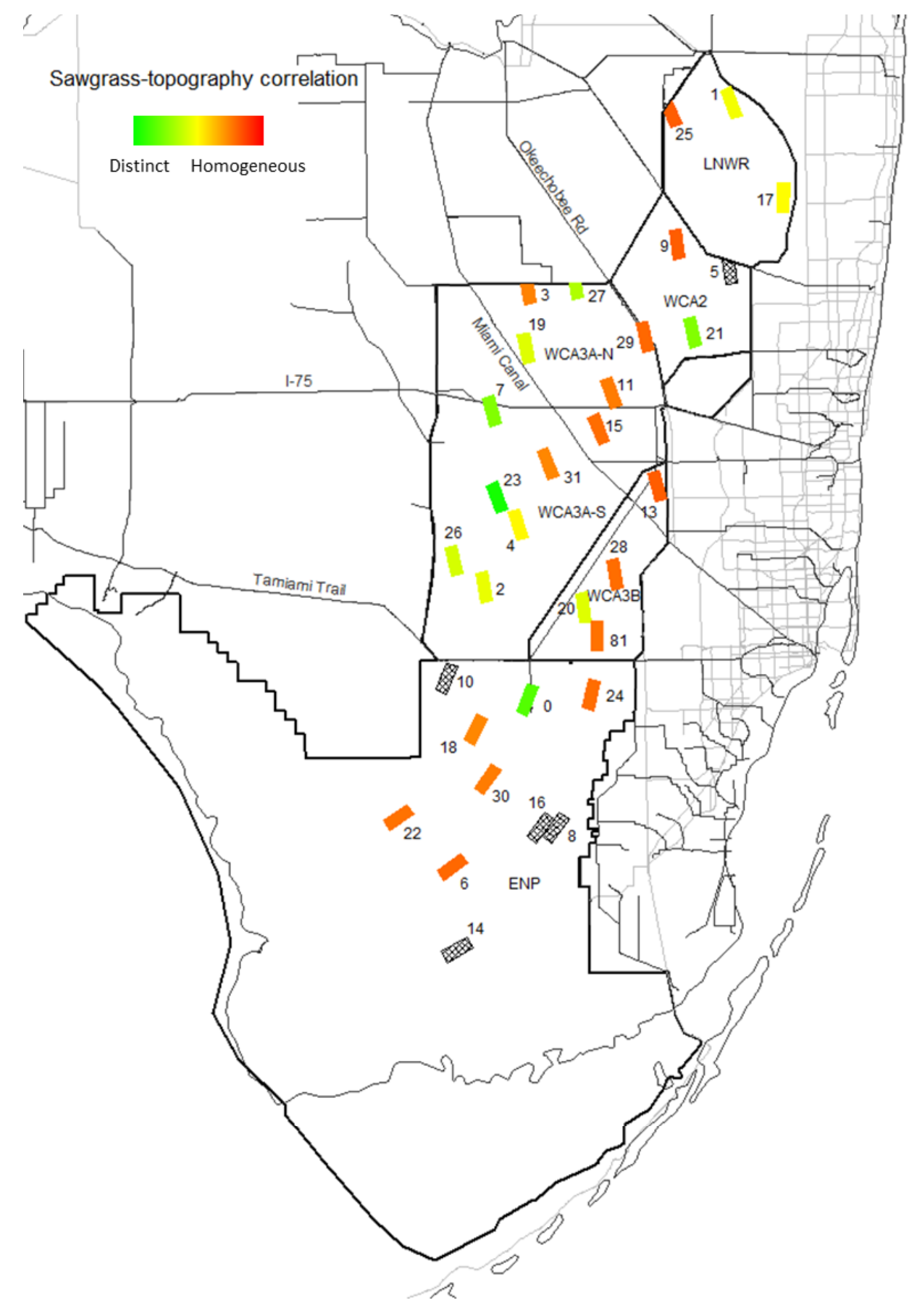

Figure 21. Sawgrass-MWD correlation across the Ridge and Slough landscape. Green PSUs are most distinct and red the most homogeneous. Black hashed PSUs in the Everglades National Park are located outside the historic Ridge and Slough landscape. Dense stands of cattail prohibited sampling of PSU 5 in WCA 2. 


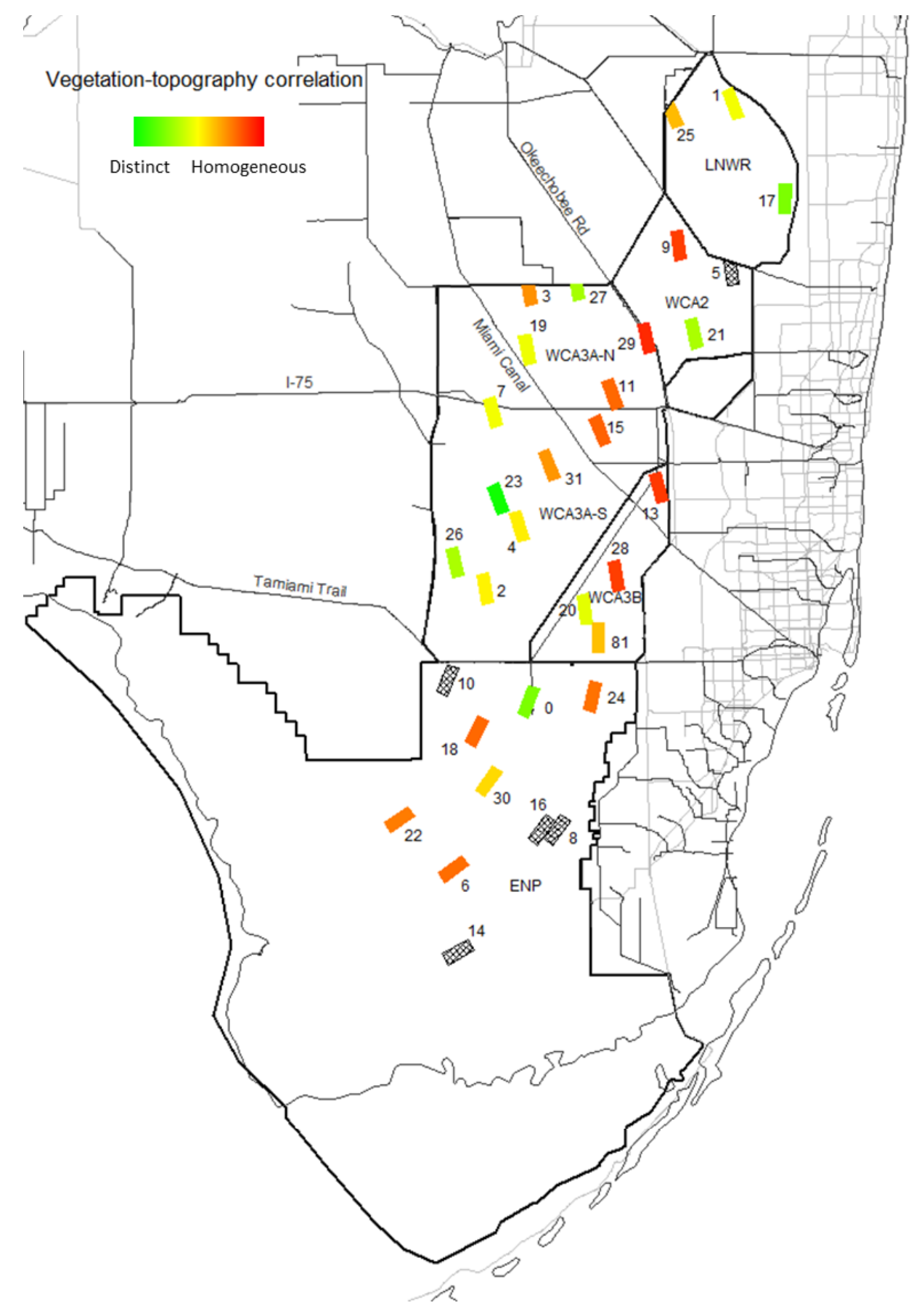

Figure 22. Mantel $r$ vegetation-topography across the Ridge and Slough landscape. Green PSUs are most distinct and red the most homogeneous. Black hashed PSUs in the Everglades National Park are located outside the historic Ridge and Slough landscape. Dense stands of cattail prohibited sampling of PSU 5 in WCA 2. 


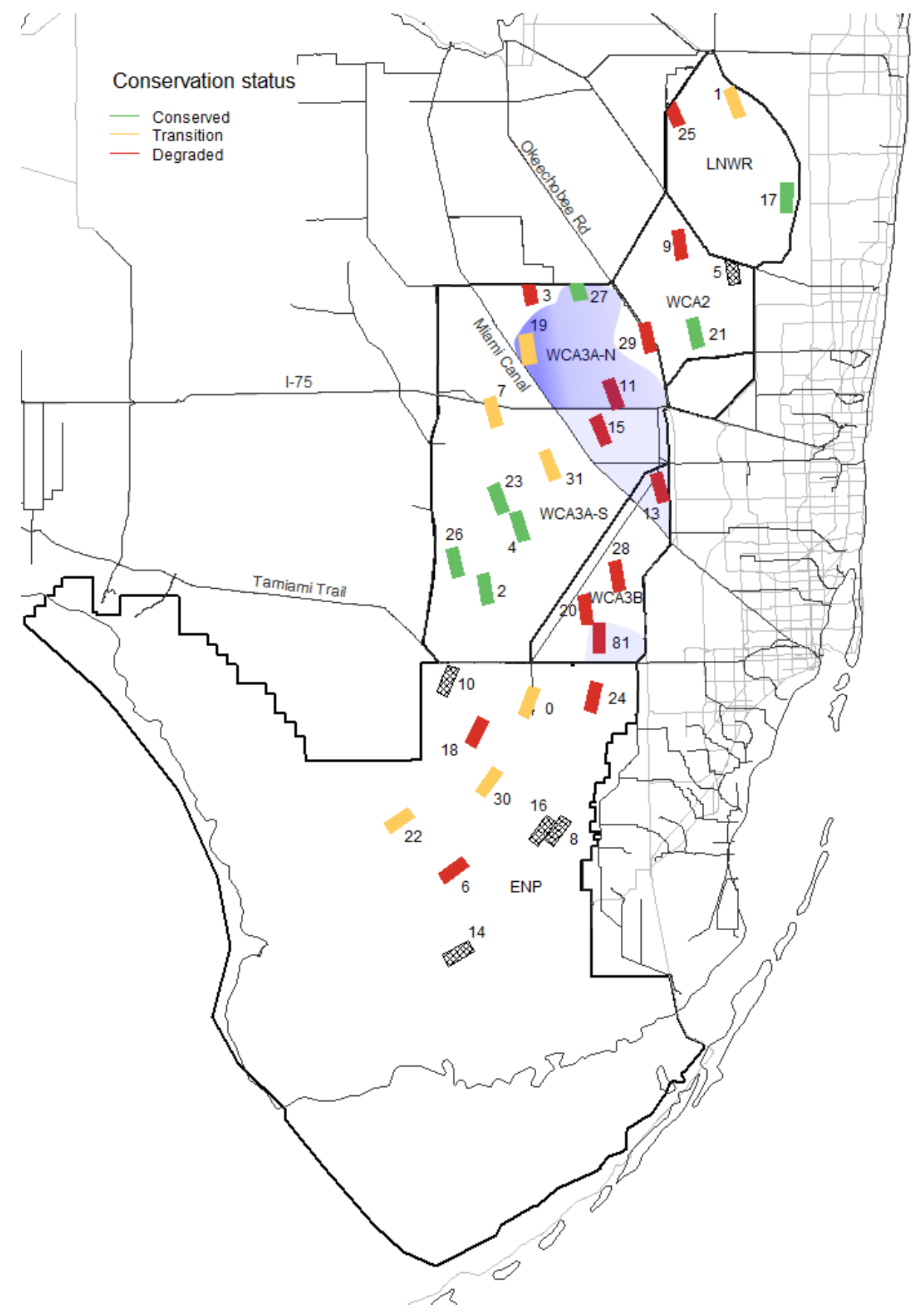

Figure 23. Conservation status for each PSU across the Ridge and Slough landscape. Green (PSUs 2, 4, 17, 21, 23, 26, 27); conserved vegetation community distinctness (high distinctness) and topography (high variation). Red (PSUs 3, 6, 9, 11, 13, 15, 18, 20, 24, 25, 28, 29, 81); both degraded vegetation community distinctness and topography. Yellow (PSUs 0, 1, 7, 19, 22, 30, 31) PSUs were found to have conserved vegetation community distinctness and degraded topographic variation. Black hashed PSUs in the Everglades National Park are located outside the historic Ridge and Slough landscape. Dense stands of cattail prohibited sampling of PSU 5 in WCA 2. Darkened areas are areas significantly affected by cattail (Typha Domingensis) which may distort the interpretation of both vegetation community distinctness and topographic variation measures in this study. 


\section{References}

Allen, C. D., and D. D. Breshears. 1998. Drought-induced shift of a forest-woodland ecotone: rapid landscape response to climate variation. Proceedings of the National Academy of Sciences 95:14839-14842.

Armentano, T. V., J. P. Sah, M. S. Ross, D. T. Jones, H. C. Cooley, and C. S. Smith. 2006. Rapid responses of vegetation to hydrological changes in Taylor Slough, Everglades National Park, Florida, USA. Hydrobiologia 569:293-309.

Bais, H. P., T. L. Weir, L. G. Perry, S. Gilroy, and J. M. Vivanco. 2006. The role of root exudates in rhizosphere interactions with plants and other organisms. Annual Review of Plant Biology 57:233-266.

Beckage, B., W. J. Platt, M. G. Slocum, and B. Panko. 2003. Influence of the EI Nino Southern Oscillation on fire regimes in the Florida Everglades. Ecology 84:31243130 .

Beisner, B. E., D. T. Haydon, and K. Cuddington. 2003. Alternative stable states in ecology. Frontiers in Ecology and the Environment 1:376-382.

Belanger, T. V., D. J. Scheidt, and J. R. Platko. 1989. Effects of nutrient enrichment on the Florida Everglades. Lake and Reservoir Management 5:101-111.

Belyea, L. R., and R. S. Clymo. 2001. Feedback control of the rate of peat formation. Proceedings of the Royal Society of London. Series B: Biological Sciences 268:1315-1321.

Bernhardt, C. E., and D. A. Willard. 2009. Response of the Everglades ridge and slough landscape to climate variability and 20th-century water management. Ecological Applications 19:1723-1738.

Busch, D. E., W. F. Loftus, and O. L. Bass. 1998. Long-term hydrologic effects on marsh plant community structure in the southern Everglades. Wetlands 18:230-241.

Callaway, R. M., and L. R. Walker. 1997. Competition and facilitation: a synthetic approach to interactions in plant communities. Ecology 78:1958-1965.

Carpenter, S. R., and W. A. Brock. 2006. Rising variance: a leading indicator of ecological transition. Ecology Letters 9:311-318.

Casanova, M. T., and M. A. Brock. 2000. How do depth, duration and frequency of flooding influence the establishment of wetland plant communities? Plant Ecology 147:237-250.

Chase, J. M. 2003. Community assembly: when should history matter? Oecologia 136:489-498. 
Cheng, Y., M. Stieglitz, G. Turk, and V. Engel. 2011. Effects of anisotropy on pattern formation in wetland ecosystems. Geophysical Research Letters 38.

Childers, D. L., R. F. Doren, R. Jones, G. B. Noe, M. Rugge, and L. J. Scinto. 2003. Decadal change in vegetation and soil phosphorus pattern across the Everglades landscape. Journal of Environmental Quality 32:344-362.

Childers, D. L., D. Iwaniec, D. Rondeau, G. Rubio, E. Verdon, and C. J. Madden. 2006. Responses of sawgrass and spikerush to variation in hydrologic drivers and salinity in Southern Everglades marshes. Hydrobiologia 569:273-292.

Clymo, R. S. 1984. The limits to peat bog growth. Philosophical Transactions of the Royal Society of London. B, Biological Sciences 303:605-654.

Cohen, M. J., D. L. Watts, J. B. Heffernan, and T. Z. Osborne. 2011. Reciprocal biotic control on hydrology, nutrient gradients, and landform in the greater Everglades. Critical Reviews in Environmental Science and Technology 41:395-429.

Combroux, I. C. S., and G. Bornette. 2004. Propagule banks and regenerative strategies of aquatic plants. Journal of Vegetation Science 15:13-20.

Combroux, I. C. S., G. Bornette, and C. Amoros. 2002. Plant regenerative strategies after a major disturbance: the case of a riverine wetland restoration. Wetlands 22:234-246.

Connell, J. H. 1983. On the prevalence and relative importance of interspecific competition: evidence from field experiments. American Naturalist:661-696.

Corenblit, D., E. Tabacchi, J. Steiger, and A. M. Gurnell. 2007. Reciprocal interactions and adjustments between fluvial landforms and vegetation dynamics in river corridors: A review of complementary approaches. Earth-Science Reviews 84:56-86.

Craft, C. B., J. Vymazal, and C. J. Richardson. 1995. Response of everglades plant communities to nitrogen and phosphorus additions. Wetlands 15:258-271.

Crain, C. M., and M. D. Bertness. 2005. Community impacts of a tussock sedge: is ecosystem engineering important in benign habitats? Ecology 86:2695-2704.

D’Odorico, P., V. Engel, J. A. Carr, S. F. Oberbauer, M. S. Ross, and J. P. Sah. 2011. Tree-grass coexistence in the Everglades freshwater system. Ecosystems 14:298-310.

Daoust, R. J., and D. L. Childers. 2004. Ecological effects of low-level phosphorus additions on two plant communities in a neotropical freshwater wetland ecosystem. Oecologia 141:672-686. 
Davis, S. M., L. H. Gunderson, W. A. Park, J. R. Richardson, and J. E. Mattson. 1994. Landscape dimension, composition, and function in a changing Everglades ecosystem. Pages 419-444 in S. Davis and J. Ogden, editors. Everglades: the Ecosystem and its Restoration. St. Lucia Press, Del Ray Beach, Florida.

Davis, S. M., and J. C. Ogden. 1994. Everglades: the ecosystem and its restoration. St. Lucia Press, Del Ray Beach, Florida.

Douglas, M. S. 1947. The Everglades: river of grass. Pineapple Press Inc.

Eppinga, M. B., M. Rietkerk, L. R. Belyea, M. B. Nilsson, P. C. D. Ruiter, and M. J. Wassen. 2010. Resource contrast in patterned peatlands increases along a climatic gradient. Ecology 91:2344-2355.

Eppinga, M. B., M. Rietkerk, W. Borren, E. D. Lapshina, W. Bleuten, and M. J. Wassen. 2008. Regular surface patterning of peatlands: confronting theory with field data. Ecosystems 11:520-536.

Eppinga, M. B., M. Rietkerk, M. J. Wassen, and P. C. Ruiter. 2007. Linking habitat modification to catastrophic shifts and vegetation patterns in bogs. Plant Ecology 200:53-68.

Feeley, K. J., and E. M. Rehm. 2012. Amazon's vulnerability to climate change heightened by deforestation and man-made dispersal barriers. Global Change Biology 18:3606-3614.

Fennema, R. J., C. J. Neidrauer, R. A. Johnson, T. K. MacVicar, and W. A. Perkins. 1994. A computer model to simulate natural Everglades hydrology. Everglades: The Ecosystem and its restoration. St. Lucie Press, Delray Beach:249-289.

Fortin, M.-J., M. R. Dale, and J. van Hoef. 2002. Spatial analysis in ecology. in A. H. ElShaarawi and W. W. Piegorsch, editors. Encyclopedia of environmetrics. John Wiley \& Sons, Ltd.

Foster, D., G. King, P. Glaser, and H. Wright Jr. 1983. Origin of string patterns in boreal peatlands. Nature 306:256-258.

Foti, R., M. del Jesus, A. Rinaldo, and I. Rodriguez-Iturbe. 2012. Hydroperiod regime controls the organization of plant species in wetlands. Proceedings of the National Academy of Sciences 109:19596-19600.

Foti, R., M. del Jesus, A. Rinaldo, and I. Rodriguez-Iturbe. 2013. Signs of critical transition in the Everglades wetlands in response to climate and anthropogenic changes. Proceedings of the National Academy of Sciences 110:6296-6300.

Gaiser, E. E. 2009. Periphyton as an indicator of restoration in the Florida Everglades. Ecological Indicators 9:S37-S45. 
Gaiser, E. E., P. V. McCormick, S. E. Hagerthey, and A. D. Gottlieb. 2011. Landscape patterns of periphyton in the Florida Everglades. Critical Reviews in Environmental Science and Technology 41:92-120.

Gaiser, E. E., L. J. Scinto, J. H. Richards, K. Jayachandran, D. L. Childers, J. C. Trexler, and R. D. Jones. 2004. Phosphorus in periphyton mats provides the best metric for detecting low-level P enrichment in an oligotrophic wetland. Water Research 38:507-516.

Gaiser, E. E., P. Sullivan, F. A. Tobias, A. J. Bramburger, and J. C. Trexler. 2013. Boundary Effects on Benthic Microbial Phosphorus Concentrations and Diatom Beta Diversity in a Hydrologically-modified, Nutrient-limited Wetland. Wetlands:1-10.

Gilad, E., J. Von Hardenberg, A. Provenzale, M. Shachak, and E. Meron. 2004. Ecosystem engineers: from pattern formation to habitat creation. Physical Review Letters 93:98105.

Givnish, T. J., J. C. Volin, V. D. Owen, V. C. Volin, J. D. Muss, and P. H. Glaser. 2008. Vegetation differentiation in the patterned landscape of the central Everglades: importance of local and landscape drivers. Global Ecology and Biogeography 17:384-402.

Gleason, P. J., and P. Stone. 1994. Age, origin, and landscape evolution of the Everglades peatland. Pages 149-197 in S. M. Davis and J. C. Ogden, editors. Everglades: the Ecosystem and its Restoration. St. Lucie Press, Boca Raton, FL, 323-40.

Gosz, J. R. 1992. Gradient analysis of ecological change in time and space: implications for forest management. Ecological Applications:248-261.

Gottlieb, A. D., J. H. Richards, and E. E. Gaiser. 2006. Comparative study of periphyton community structure in long and short-hydroperiod Everglades marshes. Hydrobiologia 569:195-207.

Groffman, P., J. Baron, T. Blett, A. Gold, I. Goodman, L. Gunderson, B. Levinson, M. Palmer, H. Paerl, G. Peterson, N. Poff, D. Rejeski, J. Reynolds, M. Turner, K. Weathers, and J. Wiens. 2006. Ecological thresholds: the key to successful environmental management or an important concept with no practical application? Ecosystems 9:1-13.

Gunderson, L. H. 1994. Vegetation of the Everglades: Determinants of Community Composition. Pages 323-340 in S. M. Davis and J. C. Ogden, editors. Everglades: The Ecosystem and its Restoration. St. Lucie Press, Boca Raton, FL.

Gunderson, L. H. 2001. South Florida: The reality of change and the prospects for sustainability: Managing surprising ecosystems in southern Florida. Ecological Economics 37:371-378. 
Gunderson, L., and S. S. Light. 2006. Adaptive management and adaptive governance in the everglades ecosystem. Policy Sciences 39:323-334.

Heffernan, J. B., D. L. Watts, and M. J. Cohen. 2013. Discharge competence and pattern formation in peatlands: a meta-ecosystem model of the Everglades ridge-slough landscape. PloS one 8:e64174.

Herndon, A., L. Gunderson, and J. Stenberg. 1991. Sawgrass (Cladium jamaicense) survival in a regime of fire and flooding. Wetlands 11:17-28.

Jackson, M. B., and T. D. Colmer. 2005. Response and adaptation by plants to flooding stress. Annals of Botany 96:501-505.

Kantvilas, G., and P. R. Minchin. 1989. An analysis of epiphytic lichen communities in Tasmanian cool temperate rainforest. Vegetatio 84:99-112.

Kaplan, D. A., R. Paudel, M. J. Cohen, and J. W. Jawitz. 2012. Orientation matters: Patch anisotropy controls discharge competence and hydroperiod in a patterned peatland. Geophysical Research Letters 39.

Kark, S., and B. J. van Rensburg. 2006. Ecotones: marginal or central areas of transition? Israel Journal of Ecology and Evolution 52:29-53.

Keddy, P. A. 2010. Wetland ecology: principles and conservation. Cambridge University Press.

Kirkman, L. K., M. B. Drew, L. T. West, and E. R. Blood. 1998. Ecotone characterization between upland longleaf pine/wiregrass stands and seasonally-ponded isolated wetlands. Wetlands 18:346-364.

Kruskal, J. B. 1964. Multidimensional scaling by optimizing goodness of fit to a nonmetric hypothesis. Psychometrika 29:1-27.

Larsen, L., N. Aumen, C. Bernhardt, V. Engel, T. Givnish, S. Hagerthey, J. Harvey, L. Leonard, P. McCormick, C. Mcvoy, G. Noe, M. Nungesser, K. Rutchey, F. Sklar, T. Troxler, J. Volin, and D. Willard. 2011. Recent and historic drivers of landscape change in the Everglades ridge, slough, and tree island mosaic. Critical Reviews in Environmental Science and Technology 41:344-381.

Larsen, L. G., and J. W. Harvey. 2010. How vegetation and sediment transport feedbacks drive landscape change in the Everglades and wetlands worldwide. The American Naturalist 176:E66-E79.

Larsen, L. G., Judson W. Harvey, and J. P. Crimaldi. 2007. A delicate balance: ecohydrological feedbacks governing landscape morphology in a lotic peatland. Ecological Monographs 77:591-614.

Levin, S. A., and R. T. Paine. 1974. Disturbance, patch formation, and community structure. Proceedings of the National Academy of Sciences 71:2744-2747. 
Levine, J. M., and D. J. Murrell. 2003. The community-level consequences of seed dispersal patterns. Annual Review of Ecology, Evolution, and Systematics:549574.

Light, S. S., and J. W. Dineen. 1994. Water control in the Everglades: a historical perspective. Everglades: The Ecosystem and its Restoration. St. Lucie Press, Delray Beach, FL:47-84.

Liu, Z., J. C. Volin, V. Dianne Owen, L. G. Pearlstine, J. R. Allen, F. J. Mazzotti, and A. L. Higer. 2009. Validation and ecosystem applications of the EDEN water-surface model for the Florida Everglades. Ecohydrology 2:182-194.

Lockwood, J. L., M. S. Ross, and J. P. Sah. 2003. Smoke on the water: the interplay of fire and water flow on Everglades restoration. Frontiers in Ecology and the Environment 1:462-468.

Loveless, C. M. 1959. A study of the vegetation in the Florida Everglades. Ecology 40:29.

MacArthur, R., and R. Levins. 1964. Competition, habitat selection, and character displacement in a patchy environment. Proceedings of the National Academy of Sciences of the United States of America 51:1207.

Magee, T. K., and M. E. Kentula. 2005. Response of wetland plant species to hydrologic conditions. Wetlands Ecology and Management 13:163-181.

McCormick, P. V., S. Newman, and L. W. Vilchek. 2008. Landscape responses to wetland eutrophication: loss of slough habitat in the Florida Everglades, USA. Hydrobiologia 621:105-114.

McLean, A. R., J. C. Ogden, and E. E. Williams. 2002. Comprehensive Everglades Restoration Plan.

McVoy, C. W., W. P. Said, J. Obeysekera, J. V. Arman, and T. Dreschel. 2011. Landscapes and Hydrology of the Predrainage Everglades. University Press of Florida.

Milchunas, D. G., and W. K. Lauenroth. 1995. Inertia in plant community structure: state changes after cessation of nutrient-enrichment stress. Ecological Applications 5:452-458.

Miller, R. C., and J. B. Zedler. 2003. Responses of native and invasive wetland plants to hydroperiod and water depth. Plant Ecology 167:57-69.

Mitsch, W. J., and J. G. Gosselink. 2000. The value of wetlands: importance of scale and landscape setting. Ecological Economics 35:25-33.

Mitsch, W. J., and J. G. Gosselink. 2011. Wetlands. John Wiley \& Sons. 
Morellet, N., J.-M. Gaillard, A. J. M. Hewison, P. Ballon, Y. Boscardin, P. Duncan, and F. Klein. 2007. Indicators of ecological change: new tools for managing populations of large herbivores. Ecology 44:634-643.

Newman, S., J. B. Grace, and J. W. Koebel. 1996. Effects of nutrients and hydroperiod on Typha, Cladium, and Eleocharis: implications for Everglades restoration. Ecological Applications 6:774-783.

Niemi, G. J., and M. E. McDonald. 2004. Application of ecological indicators. Annual Review of Ecology, Evolution, and Systematics:89-111.

Noon, K. F. 1996. A model of created wetland primary succession. Landscape and Urban Planning 34:97-123.

Nungesser, M. 2011. Reading the landscape: temporal and spatial changes in a patterned peatland. Wetlands Ecology and Management 19:475-493.

Ogden, J. C. 2005. Everglades ridge and slough conceptual ecological model. Wetlands 25:810-820.

Oksanen, J., R. Kindt, and B. O'Hara. 2005. Vegan: R functions for vegetation ecologists. URL: http://cc.oulu.fi/jarioksa/softhelp/vegan.html.

Olmsted, I., and T. V. Armentano. 1997. Vegetation of Shark Slough, Everglades National Park. SFNRC Technical.

Pearlstine, L., A. Higer, M. Palaseanu, I. Fujisaki, and F. Mazzotti. 2007. Spatially continuous interpolation of water stage and water depths using the Everglades Depth Estimation Network (EDEN). IFAS CIR1521.

Peltzer, D. A. 2001. Plant responses to competition and soil origin across a prairie-forest boundary. Journal of Ecology 89:176-185.

Post, D. M., M. W. Doyle, J. L. Sabo, and J. C. Finlay. 2007. The problem of boundaries in defining ecosystems: a potential landmine for uniting geomorphology and ecology. Geomorphology 89:111-126.

R Development Core Team. 2011. R: A language and environment for statistical computing. R Foundation for Statistical Computing, Vienna, Austria.

Richardson, C. 2010. The Everglades: North America's subtropical wetland. Wetlands Ecology and Management 18:517-542.

Ries, L., R. J. Fletcher Jr, J. Battin, and T. D. Sisk. 2004. Ecological responses to habitat edges: mechanisms, models, and variability explained. Annual Review of Ecology, Evolution, and Systematics:491-522.

Rietkerk, M., S. C. Dekker, P. C. De Ruiter, and J. Van De Koppel. 2004. Self-organized patchiness and catastrophic shifts in ecosystems. Science 305:1926-1929. 
Rietkerk, M., and J. van de Koppel. 2008. Regular pattern formation in real ecosystems. Trends in Ecology \& Evolution 23:169-175.

Ross, M. S., D. L. Reed, J. P. Sah, P. L. Ruiz, and M. T. Lewin. 2003. Vegetation:environment relationships and water management in Shark Slough, Everglades National Park. Wetlands Ecology and Management 11:291-303.

Ross, M. S., and J. P. Sah. 2011. Forest Resource Islands in a Sub-tropical Marsh: SoilSite Relationships in Everglades Hardwood Hammocks. Ecosystems 14:632645.

Sah, J. P., M. S. Ross, S. Saha, P. Minchin, and J. Sadle. 2013. Trajectories of vegetation response to water management in Taylor Slough, Everglades National Park, Florida. Wetlands:1-15.

Sarkar, D. 2010. lattice: Lattice graphics. R package version 0.19-13, URL http://CRAN. R-project. org/package $=$ lattice.

Scheffer, M., J. Bascompte, W. A. Brock, V. Brovkin, S. R. Carpenter, V. Dakos, H. Held, E. H. van Nes, M. Rietkerk, and G. Sugihara. 2009. Early-warning signals for critical transitions. Nature 461:53-59.

Scheffer, M., S. Carpenter, J. A. Foley, C. Folke, and B. Walker. 2001. Catastrophic shifts in ecosystems. Nature 413:591-596.

Scheffer, M., and S. R. Carpenter. 2003. Catastrophic regime shifts in ecosystems: linking theory to observation. Trends in Ecology \& Evolution 18:648-656.

SCT. 2003. The role of flow in the Everglades ridge and slough landscape. Pages 1-62. South Florida Ecosystem Restoration Working Group.

Sklar, F. H., M. J. Chimney, S. Newman, P. McCormick, D. Gawlik, S. Miao, C. McVoy, W. Said, J. Newman, and C. Coronado. 2005. The ecological-societal underpinnings of Everglades restoration. Frontiers in Ecology and the Environment 3:161-169.

Sklar, F. H., and A. van der Valk (Eds.). 2002. Tree islands of the Everglades: Dordrecht: Kluwer Academic Publishers.

Sklar, F., C. McVoy, R. Van Zee, D. Gawlik, D. Swift, W. Park, C. Fitz, Y. Wu, D. Rudnick, T. Fontaine, and others. 1999. Hydrologic Needs: The effects of altered hydrology on the Everglades. Everglades Interim Report, SFWMD, West Palm Beach, FL, USA.

Smith, C. M. S., M. S. Cresser, and R. D. J. Mitchell. 1993. Sensitivity to acid deposition of dystrophic peat in Great Britain. Ambio:22-26.

Sousa, W. P. 1984. The role of disturbance in natural communities. Annual Review of Ecology and Systematics 15:353-391. 
Spence, D. H. N. 1982. The zonation of plants in freshwater lakes. Advances in ecological research 12:37-125.

Stachowicz, J. J. 2001. Mutualism, facilitation, and the structure of ecological communities. Bioscience 51:235-246.

Stallins, J. A. 2006. Geomorphology and ecology: Unifying themes for complex systems in biogeomorphology. Geomorphology 77:207-216.

Stephens, J. C. 1956. Subsidence of organic soils in the Florida Everglades. Soil Science Society of America Journal 20:77-80.

Stevens Jr, D. L., and A. R. Olsen. 2004. Spatially balanced sampling of natural resources. Journal of the American Statistical Association 99:262-278.

Strayer, D. L., M. E. Power, W. F. Fagan, S. T. Pickett, and J. Belnap. 2003. A classification of ecological boundaries. BioScience 53:723-729.

Todd, M. J., R. Muneepeerakul, D. Pumo, S. Azaele, F. Miralles-Wilhelm, A. Rinaldo, and I. Rodriguez-Iturbe. 2010. Hydrological drivers of wetland vegetation community distribution within Everglades National Park, Florida. Advances in Water Resources 33:1279-1289.

Tylianakis, J. M., T. Tscharntke, and O. T. Lewis. 2007. Habitat modification alters the structure of tropical host-parasitoid food webs. Nature 445:202-205.

Urban, N. H., S. M. Davis, and N. G. Aumen. 1993. Fluctuations in sawgrass and cattail densities in Everglades Water Conservation Area 2A under varying nutrient, hydrologic and fire regimes. Aquatic Botany 46:203-223.

Van der Valk, A. G. 1981. Succession in wetlands: a Gleasonian approach. Ecology 62:688-696.

Vivanco, J. M., H. P. Bais, F. R. Stermitz, G. C. Thelen, and R. M. Callaway. 2004. Biogeographical variation in community response to root allelochemistry: novel weapons and exotic invasion. Ecology Letters 7:285-292.

Walker, B., A. Kinzig, and J. Langridge. 1999. Plant attribute diversity, resilience, and ecosystem function: The nature and significance of dominant and minor species. Ecosystems 2:95-113.

Watts, D. L., M. J. Cohen, J. B. Heffernan, and T. Z. Osborne. 2010. Hydrologic modification and the loss of self-organized patterning in the ridge-slough mosaic of the Everglades. Ecosystems 13:813-827.

Weiher, E., and P. A. Keddy. 1995. The assembly of experimental wetland plant communities. Oikos:323-335. 
Van Wesenbeeck, B. K., J. Van De Koppel, P. M. J. Herman, and T. J. Bouma. 2008. Does scale-dependent feedback explain spatial complexity in salt-marsh ecosystems? Oikos 117:152-159.

White, P. S. 1994. Synthesis: vegetation pattern and process in the Everglades ecosystem. Everglades: the ecosystem and its restoration. St Lucia Press, St Lucia:445-460.

Wickham, H. 2008. ggplot2: An implementation of the grammar of graphics. $\mathrm{R}$ package version 0.7, URL: http://CRAN. R-project. org/package= ggplot2.

Wiens, J. A., C. S. Crawford, and J. R. Gosz. 1985. Boundary dynamics: a conceptual framework for studying landscape ecosystems. Oikos:421-427.

Wu, Y., N. Wang, and K. Rutchey. 2006. An analysis of spatial complexity of ridge and slough patterns in the Everglades ecosystem. Ecological Complexity 3:183-192.

Zedler, J. B. 2000. Progress in wetland restoration ecology. Trends in Ecology \& Evolution 15:402-407.

Zedler, J. B., and S. Kercher. 2004. Causes and consequences of invasive plants in wetlands: opportunities, opportunists, and outcomes. Critical Reviews in Plant sciences 23:431-452.

Zweig, C. L., and W. M. Kitchens. 2008. Effects of landscape gradients on wetland vegetation communities: information for large-scale restoration. Wetlands 28:1086-1096.

Zweig, C. L., and W. M. Kitchens. 2009. Multi-state succession in wetlands: a novel use of state and transition models. Ecology 90:1900-1909. 